\title{
Evolutionary analysis of chloroplast tRNA of Gymnosperm revealed the novel structural variation and evolutionary aspect
}

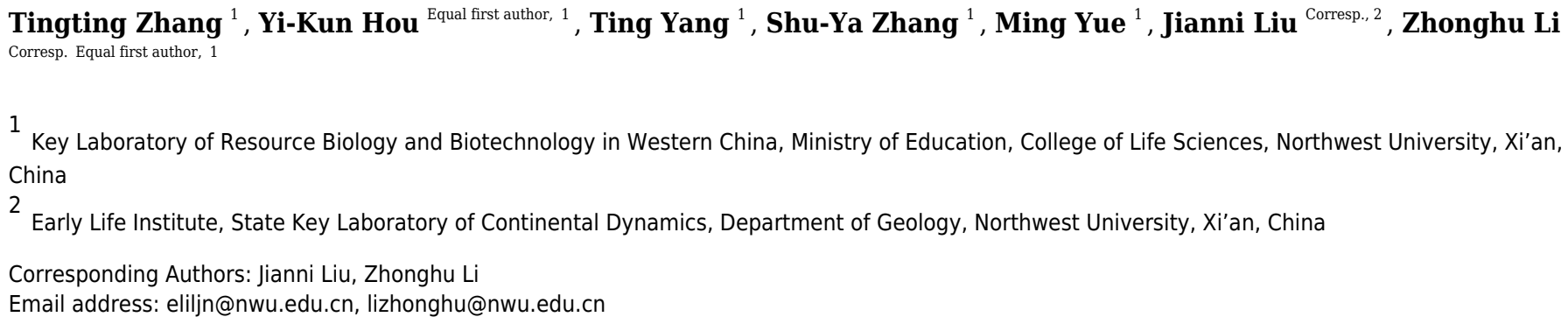

Gymnosperms such as ginkgo, conifers, cycads, and gnetophytes are vital components of land ecosystems, and they have significant economic and ecologic value, as well as important roles as forest vegetation. In this study, we investigated the structural variation and evolution of chloroplast transfer RNAs (tRNAs) in gymnosperms. Chloroplasts are important organelles in photosynthetic plants. tRNAs are key participants in translation where they act as adapter molecules between the information level of nucleic acids and functional level of proteins. The basic structures of gymnosperm chloroplast tRNAs were found to have family-specific conserved sequences. The tRNA $\Psi$-loop was observed to contain a conforming sequence, i.e., U-U-C-N-A- $\mathrm{N}_{2}$. In gymnosperms, tRNA ${ }^{\text {lle }}$ was found to encode a "CAU" anticodon, which is usually encoded by tRNA ${ }^{\text {Met }}$. Phylogenetic analysis suggested that plastid tRNAs have a common polyphyletic evolutionary pattern, i.e., rooted in abundant common ancestors. Analyses of duplication and loss events in chloroplast tRNAs showed that gymnosperm tRNAs have experienced little more gene loss than gene duplication. Transition and transversion analysis showed that the tRNAs are isoacceptor specific and they have experienced unequal evolutionary rates. These results provide new insights into the structural variation and evolution of gymnosperm chloroplast tRNAs, which may improve our comprehensive understanding of the biological characteristics of the tRNA family. 


\section{Evolutionary analysis of chloroplast tRNA of}

3 Gymnosperm revealed the novel structural variation 4 and evolutionary aspect

5

6

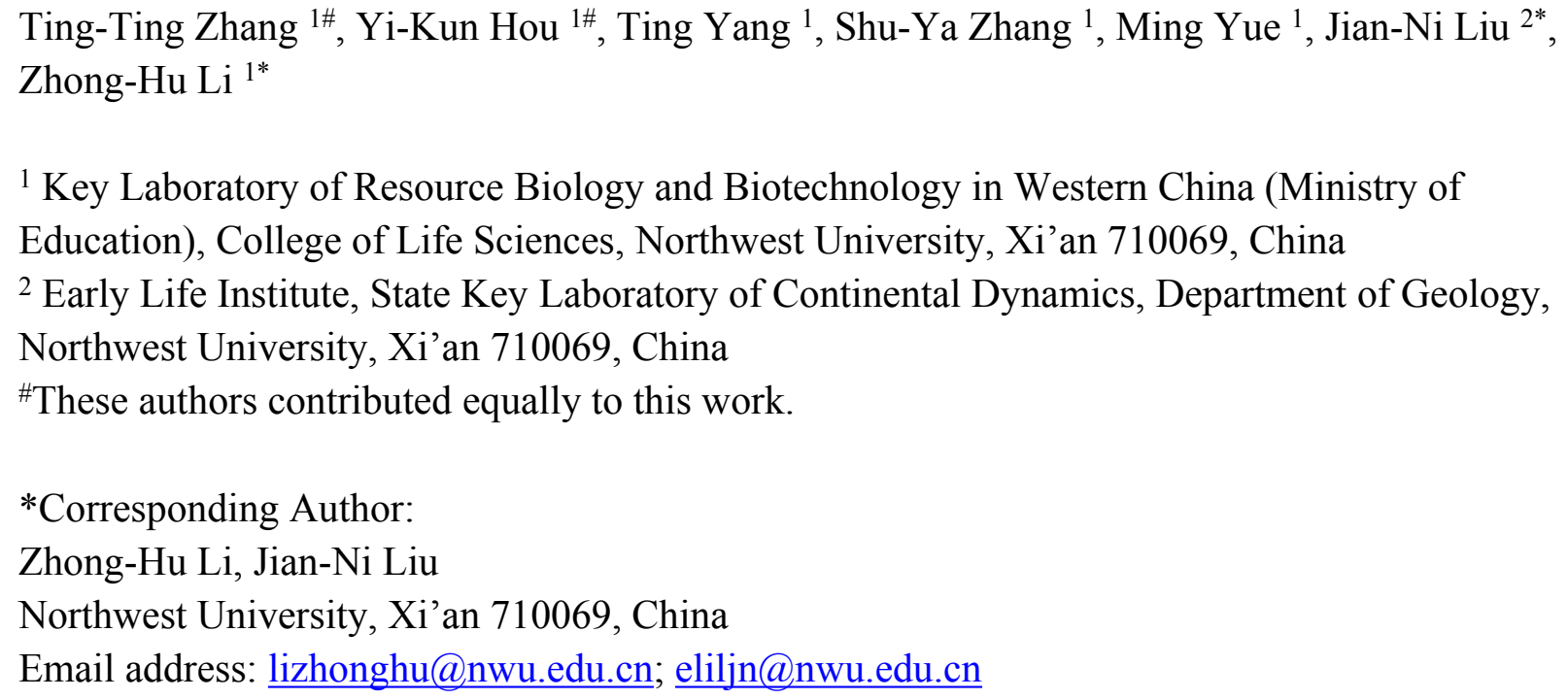

\section{Abstract}

Gymnosperms such as ginkgo, conifers, cycads, and gnetophytes are vital components of land ecosystems, and they have significant economic and ecologic value, as well as important roles as forest vegetation. In this study, we investigated the structural variation and evolution of chloroplast transfer RNAs (tRNAs) in gymnosperms. Chloroplasts are important organelles in photosynthetic plants. tRNAs are key participants in translation where they act as adapter molecules between the information level of nucleic acids and functional level of proteins. The basic structures of gymnosperm chloroplast tRNAs were found to have family-specific conserved sequences. The tRNA $\Psi$-loop was observed to contain a conforming sequence, i.e., UU-C-N-A-N ${ }_{2}$. In gymnosperms, tRNA Ile was found to encode a "CAU" anticodon, which is usually encoded by tRNA ${ }^{\text {Met }}$. Phylogenetic analysis suggested that plastid tRNAs have a common polyphyletic evolutionary pattern, i.e., rooted in abundant common ancestors. Analyses of duplication and loss events in chloroplast tRNAs showed that gymnosperm tRNAs have experienced little more gene loss than gene duplication. Transition and transversion analysis showed that the tRNAs are iso-acceptor specific and they have experienced unequal evolutionary rates. These results provide new insights into the structural variation and evolution of gymnosperm chloroplast tRNAs, which may improve our comprehensive understanding of the biological characteristics of the tRNA family. 
40

41

42

43

44

45

46

47

48

49

50

51

52

53

54

55

56

57

58

59

60

61

62

63

64

65

66

67

68

69

70

71

72

73

74

75

76

77

78

\section{Introduction}

Gymnosperms originated in the Paleozoic Devonian Period (about 385 million years ago), and they are key groups in terms of the transformation from spore reproduction to seed reproduction in higher plants (Gerrienne et al., 2004; Crisp \& Cook, 2011). According to the latest phylogenetic classification, gymnosperm species are divided into eight orders, 12 families, 84 genera, and more than 1,000 species (Wang \& Ran, 2014). Gymnosperms include ginkgo, cycads, conifers, and gnetophytes, which are grown in forests as important timber species and they provide raw materials for human usage, such as fiber, resin, and tannin (Christenhusz et al., 2010). In addition, gymnosperms include some important threatened plants, where $40 \%$ are at high risk of extinction (Forest et al., 2018). Recent phylogenetic and evolutionary studies of gymnosperms have demonstrated the rapid evolution of mitochondrial $(\mathrm{mt})$ genes and provided further evidence of sister relationship between conifers and Gnetales (Ran, Gao \& Wang, 2010). The high levels of genetic diversity and population differentiation among the Pinus species in gymnosperms have been studied based on plastid DNA markers (Liu et al., 2014). Other studies have indicated patterns related to the physiological ecology, phylogenetic relationships, and population genetic structure of gymnosperm species (Yu et al., 2014; Li et al., 2015; Dong et al., 2016). However, these studies mainly considered the phylogeny and evolution at the whole populations level. Thus, the detailed evolutionary characteristics of gymnosperms still need to be elucidated.

Chloroplasts are the site of photosynthesis and of various essential metabolic pathways, e.g., fatty acid and amino acid biosynthesis and the assimilation of nitrogen, sulfur, and selenium (Wise \& Hoober, 2006; Des Marais,2000; Knorr \& Heimann, 2001; Pilon-Smits et al., 2002; Guo et al., 2007; Kretschmer, Croll \& Kronstad, 2017). It is generally recognized that chloroplasts are derived from proto-eukaryotic symbiotic cyanobacteria that internalized in eukaryotic cells (Hiroki \& Daisuke, 2018) and evolved into central organelles. Chloroplasts have their own genome encoding about 100 proteins and they are maternally inherited organelles in most angiosperm plants (Abdallah, Salamini \& Leister, 2000; Heuertz et al., 2004; Civan et al., 2014). Among gymnosperms, paternal plastid inheritance is the typical characteristic of conifers (Fauré et al., 1994; Kaundun \& Matsumoto, 2011). Studies have shown that the chloroplast genome is quite conserved with an average evolutionary rate of $0.2-1.0 \times 10^{-9}$ per site per year, which is only one-fifth of that for the nuclear genome (Drouin, Daoud \& Xia, 2008; Duchene \& Bromham, 2013). The chloroplast genome is a covalently closed circular structure with four parts comprising the large single copy region (LSC), small single copy region (SSC), inverted repeat region A (IRa), and inverted repeat region $B$ (IRb). The two IRs have the same sequences but in the opposite direction (Wang et al., 2008; Logacheva et al., 2009; Hereward et al., 2018). Due to the independent evolution of the chloroplast genome, it is possible to construct a molecular phylogenetic tree using the chloroplast genome and without requiring any other data. Data analysis based on the conserved evolution of plastids is highly valuable for phylogenetic studies (Kim \& Suh, 2013) because it can provide reliable and useful phylogenetic information. The 
relative completeness and independence of the chloroplast genome means that it can provide valuable material for research purposes.

Transfer RNAs (tRNAs) undergo numerous post-transcriptional nucleotide modifications and they exhibit abundant chemical diversity where the bases experience methylation, formylation, and other modifications (Suzuki \& Suzuki, 2014). Chemical nucleotide modifications are frequent in tRNAs and they are important for the structure, stability, correct folding, aminoacylation, and decoding. For example, a previous analysis of the chemically synthesized $\mathrm{f}^{5} \mathrm{C} 34$-modified anticodon loop of human mt-tRNA ${ }^{\text {Met }}$ showed that $\mathrm{f}^{5} \mathrm{C} 34$ contributes to the anticodon domain structure of the mt-tRNA (Lusic et al., 2008). tRNAs comprise sequences of less than 100 polynucleotides that fold into a clover-type secondary structure and then into an L-shaped tertiary structure (Wilusz, 2015). The secondary structure of tRNAs comprises different arms as well as loops, i.e., the D-arm, acceptor arm, anticodon arm, pseudouridine arm ( $\Psi$-arm), D-loop, variable arm, anticodon loop, and pseudouridine loop ( $\Psi$ loop) (Giegé, Puglisi \& Florentz, 1993; Mizutani \& Goto, 2000). This unique structure allows tRNA to act as important bridges between the information level of nucleic acids and functional level of proteins. The vital components of tRNAs comprise an anti-codon region that discerns the messenger RNA carried by the specific codons, a 3'-CCA tail for attaching to the cognate amino acid, the $\Psi$-arm, and a $\Psi$-loop that has a relationship with the ribosome machinery (Kirchner $\&$ Ignatova, 2014). Asymmetric combinations and the divided segments in tRNA genes allow us to understand the diversity of tRNA molecules. tRNA species fulfill various functions in cellular homeostasis, regulation of gene expression and epigenetics, biogenesis, and even biological disease (Ribasd \& Dedon, 2014; Kanai, 2015; Schimmel, 2017). The evolutionary relationships determined between cyanobacteria and monocots show that tRNAs evolved polyphyletically and they originated from multiple common ancestors with a high rate of gene loss (Mohanta et al., 2017; Mohanta et al., 2019). Nevertheless, the basic details of the tRNAs in plant chloroplasts still need to be elucidated and on the diverse evolutionary features of gymnosperm tRNAs are still unclear.

In this study, we assessed all of the chloroplast genomes in 12 families of gymnosperms from eight orders. The main aims of this study were as follows: (1) to determine the diversification of nucleotides in the secondary structure of gymnosperm tRNAs; (2) to identify the detailed genomic features of chloroplast tRNAs; (3) to assess the evolutionary relationships among different chloroplast tRNAs; and (4) to evaluate the duplication or loss events that occurred in all of the tRNAs considered. Our findings provide important insights into the biological characteristics and evolutionary variation of the tRNA family.

\section{Materials \& Methods}

Annotation and identification of chloroplast tRNA sequences in gymnosperms

We downloaded complete chloroplast genomes for 12 representative gymnosperms in eight orders from the National Center for Biotechnology Information database (NCBI, https://www.ncbi.nlm.nih.gov/). The gymnosperm species investigated were: Cycas debaoensis 
119 Y. C. Zhong \& C. J. Chen (KM459003), Dioon spinulosum Dyer ex Eichler (NC_027512), 120 Ginkgo biloba L. (NC_016986), Cedrus deodara (Roxb.) G. Don (NC_014575), Wollemia 121 nobilis W. G. Jones, K. D. Hill \& J. M. Allen (NC_027235), Retrophyllum piresii Silba C. N. 122 (KJ017081), Sciadopitys verticillata (Thunb.) Sieb. et Zucc. (NC_029734), Cunninghamia 123 lanceolata (Lamb.) Hook. (NC_021437), Taxus mairei (Lemee et Levl.) Cheng et L. K. Fu 124 (KJ123824), Welwitschia mirabilis Hook.f. (EU342371), Gnetum gnemon L. (KR476377), and 125 Ephedra equisetina Bge. (NC_011954). The gymnosperm tRNA genomes were annotated using 126 GeSeq-Annotation of Organellar Genomes tool (Tillich et al., 2017) where the parameters were

127

128

129

130

131

132

133

134

135

136

137

138

139

140

141

142

143

144

145

146

147

148

149

150

151

152

153

154

155

156

157

158 set as: circular sequence(s), chloroplast of sequence source, generate multi FASTA; BLAST protein search identity $25 \%$ for annotating plastid IR, $85 \%$ identity for BLAST rRNA, tRNA and DNA search, Embryophyta chloroplast (CDS+rRNA), third party tRNA annotator ARAGORN v1.2.38, ARWEN v1.2.3, tRNAScan-SE v2.0, and without Refseq choice.

\section{Structural analysis of chloroplast tRNAs}

ARAGORN (Laslett \& Canback, 2004) and tRNAScan-SE software (Lowe \& Eddy, 1997) were employed to analyze the sequences and the secondary structure of tRNAs in the chloroplast genomes of the involved gymnosperm plants. The default parameters were set in ARAGORN software. The parameters for tRNAScan-SE were set as: sequence source, bacterial; search mode, default; query sequences, formatted (FASTA); and genetic code for tRNA isotype prediction, universal.

\section{Phylogenetic tree construction}

A phylogenetic tree was constructed for all of the tRNAs using MEGA7.0 software (Kumar et al., 2008; Kumar, Stecher \& Tamura, 2016). To study the evolutionary details of chloroplast tRNAs in gymnosperm species, an alignment file for tRNAs was achieved by CLUSTAL Omega software before the phylogenetic tree was constructed. MEGA7 software was used to transform the alignment file into MEGA format. The phylogenetic tree was constructed with the following parameters: phylogeny reconstruction of analysis, maximum likelihood model, bootstrap method in phylogeny test, 1000 bootstrap replicates, nucleotides type, gamma distributed with invariant sites $(\mathrm{G}+\mathrm{I})$ model, five discrete gamma categories, partial deletion for gaps/missing data treatment, $95 \%$ site coverage cut-off, and very strong for branch swap filter.

\section{Transition/transversion analysis}

The sequences of the tRNA isotypes were aligned to determine the transition and transversion rates for chloroplast tRNAs in gymnosperm plants. The files covering all 20 types of tRNAs were transformed into the MEGA file format and analyzed separately using MEGA7.0 software (Kumar, Tamura \& Nei, 1994). The transition and transversion rates were analyzed for tRNAs with the following parameters: substitution pattern estimation (ML) analysis, automatic (neighbor-joining tree), maximum likelihood statistical method, nucleotide substitution type, Kimura two-parameter model, gamma distributed (G) site rates, five discrete gamma categories, 
159

160

161

162

163

164

165

166

167

168

169

170

171

172

173

174

175

176

177

178

179

180

181

182

183

184

185

186

187

188

189

190

191

192

193

194

195

196

197

198

partial deletion of gaps/missing data treatment, $95 \%$ of site coverage cut-off, and very strong branch swap filter.

Loss and duplication events analysis for tRNA genes

In order to investigate the duplication or loss events in tRNA genes, the NCBI taxonomy browser was utilized to construct the whole species tree for the 12 gymnosperm species considered. The phylogenetic tree conducted in the evolutionary study was employed as gene tree. The gene tree for the tRNAs and species tree for the gymnosperm species were submitted to Notung 2.9 software (Chen, Durand \& Farach-Colton, 2000), and then reconciled to discover duplicated and lost tRNA genes in the chloroplast genomes of gymnosperms.

\section{Results}

Genomic features of gymnosperm chloroplast tRNAs

Sequences were analyzed to identify the genomic tRNAs in the chloroplast genomes of 12 gymnosperm species comprising $C$. debaoensis, D. spinulosum, G. biloba, C. deodara, W. nobilis, R. piresii, S. verticillata, C. lanceolata, T. mairei, W. mirabilis, G. gnemon, and E. equisetina, which were obtained from the NCBI database (Table 1). The results showed that the length of the chloroplast tRNAs vary from the smallest with 64 nucleotides (nt) (tRNA Met $-C A U$ in T. mairei) to the largest with $96 \mathrm{nt}$ (tRNA ${ }^{\mathrm{Tyr}}$-AUA in W. nobilis, C. deodara, and G. biloba) (Data S1). We found that the chloroplast genomes of gymnosperm plants encode 28 to 33 tRNAs (Table 2), where D. spinulosum, C. deodara, and S. verticillata encode 31 anticodons, W. nobilis, $R$. piresii, C. lanceolata, and G. gnemon encode 32 tRNA isotypes, G. biloba, and W. mirabilis encode 33 tRNAs. Other species comprising T. mairei, E. equisetina and C. debaoensis encode 28, 28, 30 tRNA isotypes, respectively (Table 2). tRNA Ala was not found in $R$. piresii and $T$. mairei, and tRNA ${ }^{\mathrm{Val}}$ was not detected in T. mairei (Fig. S3). We also observed that all of the species do not encode selenocysteine and its suppressor tRNA (Table 2). Overall, tRNA ${ }^{\text {Ser }}$ (in $W$. nobilis) and tRNA ${ }^{\mathrm{Arg}}$ (in $W$. mirabilis) are the most abundant (four types) followed by tRNA ${ }^{\text {Leu }}$ (three types) (Table 2).

Variations in structures of chloroplast tRNAs

Some tRNAs with a loop structure in the variable region were found to be encoded in the gymnosperm chloroplast genomes (Fig. 1, Fig. 2). A novel tRNA lacking the D-arm was found in tRNA ${ }^{\text {Gly }}$ in $W$. nobilis (Fig. 3). As shown in Fig. 1 and Fig. 2, tRNA ${ }^{\text {Leu }}$, tRNA ${ }^{\text {Ser }}$, and tRNA ${ }^{\text {Tyr }}$

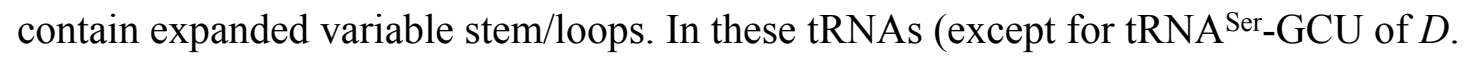
spinulosum), the anticodon loop of tRNA ${ }^{\text {Ser }}$ contains the conserved consensus sequence N-U-NG-A-A-N, and tRNAs ${ }^{\text {Leu }}$ have the consensus sequence C-U-N-A-N $2-A$. The variable loop region is predicted to fold into stem-loop structures with apical loops of 3 to $7 \mathrm{nt}$ in $\mathrm{tRNA}^{\text {Ser }}$ and several tRNA $^{\text {Leu }}$ variants. The stems contain up to $7 \mathrm{bp}$ (Fig. 1 and 2). The expanded variable loop structures may play important functions during the protein translation process in chloroplasts. 
199

200

201

202

203

204

205

206

207

208

209

210

211

212

213

214

215

216

217

218

219

220

221

222

223

224

225

226

227

228

229

230

231

232

233

234

235

236

237

238

Chloroplast genomes contain 25 to 30 anticodon-specific tRNAs

The genomes of the species analyzed were found to code for at least two copies of tRNA Met_

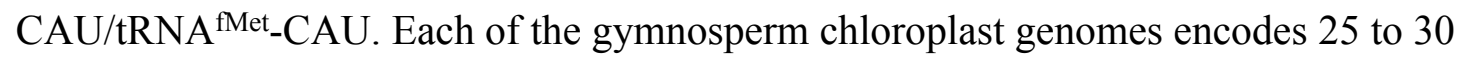
anticodon-specific tRNAs (Table 2 and Table 3), where E. equisetina encodes 25 anticodons, $T$. mairei encodes 26 anticodons, $C$. debaoensis, $S$. verticillata, and C. lanceolata encode 28 anticodons, and D. spinulosum, C. deodara, W. mirabilis, and $R$. piresii encode 29 anticodons. Other species comprising W. nobilis, G. gnemon and G. biloba encodes 30 anticodons (Table 3). tRNA ${ }^{\mathrm{Arg}}$-CCG was present in the genomes of nine gymnosperm species but absent from $C$. lanceolata, T. mairei, and E. equisetina, while tRNA Gly_UCC was lacking from C. debaoensis, $S$. verticillata, D. spinulosum, C. lanceolata, T. mairei, and E. equisetina (Table 3). The most abundant anticodons found in the chloroplast genomes were tRNA ${ }^{\text {Gly }}$-GCC, $t R N A^{\text {Pro }}-U_{G G}$, tRNA ${ }^{\text {Ser_UGA, }}$ tRNA ${ }^{\text {Ser_GCU, tRNA }}{ }^{\text {Arg-ACG, }}$, tRNA ${ }^{\text {Arg_-UCU, tRNA }}{ }^{\text {Leu_UAG, }}$, tRNA ${ }^{\text {Leu_CAA, }}$

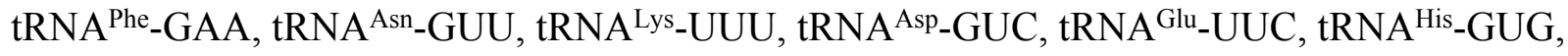

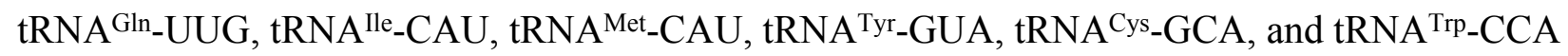
(Table 3). Two tRNA ${ }^{\text {Trp }}$ iso-acceptors are present in E. equisetina chloroplasts, compared with a single one in the other gymnosperm species analyzed in this study.

\section{Conserved gymnosperm chloroplast tRNAs}

The clover leaf-like secondary structure of a tRNA is shown in Fig. 4. In the study, we found that most tRNAs contain a "G" as the first nucleotide in the D-arm, except for tRNA ${ }^{\text {Lys }}$, tRNA ${ }^{\text {Met }}$, tRNA ${ }^{\text {Pro }}$, $\mathrm{tRNA}^{\mathrm{Thr}}$, $\mathrm{tRNA}^{\mathrm{Tyr}}$, and tRNA ${ }^{\mathrm{Val}}$. " $\mathrm{A}$ " is present in the first and the last position of the D-loop apart from tRNA ${ }^{\mathrm{Gly}}$, $\mathrm{tRNA}^{\mathrm{Ile}}$, $\mathrm{tRNA}^{\mathrm{Leu}}, \mathrm{tRNA}^{\mathrm{Met}}$, and $\mathrm{tRNA}{ }^{\mathrm{Gln}}$. In addition, in the final two positions of the $\Psi$-arm, all of the tRNAs were found to have conserved " $G-G$ " nucleotides, except for tRNA ${ }^{A r g}$, $\mathrm{tRNA}^{\mathrm{Cys}}$, $\mathrm{tRNA}^{\text {Phe }}$, and tRNA ${ }^{\mathrm{Val}}$ (Table 4). Small conserved consensus sequences were found in the $\Psi$ region. To be specific, except for tRNA ${ }^{\text {Ser }}$, the $\Psi$-loop in tRNAs was found to contain a conserved sequence comprising U-U-C-N-A-N $\mathrm{N}_{2}$ according to a multiple sequence alignment of 20 members of the tRNA gene family (Table 4).

\section{Diversification of tRNAs structures}

The diverse arms and loops of tRNAs allow the regulation and control of protein translation. Each arm and loop has a specific nucleotide composition. Our analysis based on 373 tRNAs showed that the acceptor arm of chloroplast tRNAs contains 6 bp to 7 bp (Table S1). The D-arms were found to contain 3 or 4 bp generally, with a stable " $G$ " in the initial position and " $C$ " in the last position of the D-stem 5' strand in most tRNAs (such as tRNA ${ }^{\text {Ala }}$, tRNA ${ }^{\text {Asn }}$, tRNA ${ }^{\text {Asp, }}$,

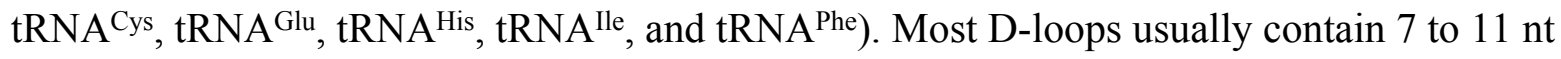
with conserved " $A$ " nucleotides at the two end locations. The anticodon arms of chloroplast tRNAs mainly contain 5 bp (90.4\%). We found that 367 (about 99\%) tRNAs contain 7 nt in their anticodon loop, thereby indicating that the sequence of the anticodon loop is highly conserved (Table 4, Table S1). The variable loops of different tRNAs contain 3 to 23nt, where those in tRNA $^{\text {Ala }}$, tRNA ${ }^{\text {Asp }}$, tRNA $^{\text {His }}$, tRNA $^{\text {Phe }}$, and tRNA ${ }^{\text {Pro }}$ contain 5 bp (Table S1). The $\Psi$-arm contains 
$2395 \mathrm{bp}$ in most of the gymnosperm chloroplast tRNAs, except for tRNA Ala and some of the $240 \mathrm{tRNA}^{\mathrm{Tr}}$, $\mathrm{tRNA}^{\mathrm{Gly}}$, $\mathrm{tRNA}^{\mathrm{Thr}}$, and tRNA ${ }^{\mathrm{Arg}}$ in chloroplast. The $\Psi$-loops of most tRNAs contain 7 $241 \mathrm{nt}$, apart from tRNA ${ }^{\mathrm{Ala}}$ and several of tRNA ${ }^{\text {Cys }}$ and $\operatorname{tRNA}^{\text {Thr }}$ (Table S1).

242

243 Gymnosperm chloroplast tRNAs derived from multiple common ancestors

244 The phylogenetic tree demonstrated the presence of three major clusters covering 64 groups and 245 the different types of all tRNAs (as shown by the different strings in Fig. S1). We detected 37 246 groups in cluster I, five in cluster II, and 22 groups in cluster III. Cluster I contains tRNA ${ }^{\mathrm{Ser}}$, $247 \mathrm{tRNA}^{\mathrm{Tyr}}, \mathrm{tRNA}^{\mathrm{His}}, \mathrm{tRNA}^{\mathrm{Gln}}, \mathrm{tRNA}^{\mathrm{Thr}}, \mathrm{tRNA}^{\text {Pro }}, \mathrm{tRNA}^{\mathrm{Gly}}, \mathrm{tRNA}^{\mathrm{Met}}, \mathrm{tRNA}^{\mathrm{Asp}}, \mathrm{tRNA}^{\mathrm{Arg}}$, $\mathrm{tRNA}^{\mathrm{Ala}}$, $248 \mathrm{tRNA}^{\mathrm{Cys}}, \mathrm{tRNA}^{\mathrm{Lys}}, \mathrm{tRNA}^{\mathrm{Glu}}$, tRNA ${ }^{\mathrm{Ile}}$, $\mathrm{tRNA}^{\mathrm{Asn}}$, $\mathrm{tRNA}^{\mathrm{Val}}$, $\mathrm{tRNA}^{\mathrm{Leu}}$, and tRNA ${ }^{\mathrm{Trp}}$. Cluster II contains tRNA ${ }^{\text {His }}$, tRNA ${ }^{\text {Ser }}$, tRNA $^{\text {Tyr }}$, and tRNA ${ }^{\text {Leu }}$. Cluster III contains tRNA ${ }^{\text {Leu }}$, tRNA ${ }^{\text {Ile }}$,

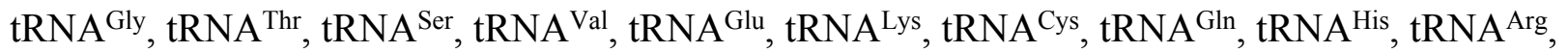
tRNA $^{\text {Phe }}$, tRNA ${ }^{A l a}$, and tRNA ${ }^{\text {Met }}$ (Fig. S1). tRNA ${ }^{\text {Ser }}$, tRNA ${ }^{\text {His }}$, and tRNA ${ }^{\text {Leu }}$ are present in cluster

253

254

255

256

257

258

259

260

261

262

263

264

265

266

267

268

269

270

271

272

273

274

275

276

277 278

I but also in cluster II and cluster III, thereby suggesting that these tRNAs evolved from multiple lineages. Most of the tRNAs were found to form more than one group in the phylogenetic tree. In cluster I, the tRNAs that formed two groups in the phylogenetic tree were identified as tRNA ${ }^{\text {Tyr }}$, tRNA $^{\mathrm{Gln}}$, $\mathrm{tRNA}^{\mathrm{Met}}$, $\mathrm{tRNA}^{\mathrm{Asp}}$, $\mathrm{tRNA}^{\mathrm{Ala}}$, $\mathrm{tRNA}^{\mathrm{Lys}}$, $\mathrm{tRNA}^{\mathrm{Ile}}$, and tRNA ${ }^{\text {Trp }}$, whereas those that clustered to form three groups were determined as tRNA ${ }^{\mathrm{Ser}}, \mathrm{tRNA}^{\mathrm{Pro}}, \mathrm{tRNA}^{\mathrm{Arg}}$, $\mathrm{tRNA}^{\mathrm{Glu}}$, tRNA $^{\mathrm{Asn}}, \mathrm{tRNA}^{\mathrm{Val}}$, and tRNA ${ }^{\mathrm{Leu}}$. Moreover, $\mathrm{tRNA}^{\mathrm{Thr}}$ clustered into four groups. In cluster II, $t_{R N A}{ }^{\text {Ser }}$ was found to form two groups. In cluster III, tRNA ${ }^{\text {Gly }}$ and tRNA ${ }^{\text {Val }}$ were found to form two groups, whereas tRNA ${ }^{\text {Thr }}$ formed three groups, tRNA ${ }^{\text {Ile }}$ formed four groups. Some tRNAs in cluster III were found to group individually, where these tRNAs containing the anticodons C-GA in tRNA ${ }^{\text {Ser }}$, U-U-C in tRNA ${ }^{\text {Glu }}$, U-U-U in tRNA ${ }^{\text {Lys }}$, G-C-A in tRNA ${ }^{\text {Cys }}$, U-U-G in tRNA ${ }^{\text {Gln }}$, GU-G in tRNA ${ }^{\text {His }}, \mathrm{U}-\mathrm{C}-\mathrm{U}$ in tRNA ${ }^{\mathrm{Arg}}$, G-A-A in tRNA ${ }^{\text {Phe }}, \mathrm{U}-\mathrm{G}-\mathrm{C}$ in tRNA ${ }^{\mathrm{Ala}}$, and C-A-U in tRNA $^{\text {Met }}$ all grouped separately (Fig. S1). The multiple groupings of different tRNAs suggest that they evolved from multiple common ancestors. Furthermore, the tRNAs presented in cluster III, i.e., tRNA ${ }^{\mathrm{Met}}(\mathrm{CAU}), \mathrm{tRNA}^{\mathrm{Thr}}$ (UGU, GGU), tRNA ${ }^{\mathrm{Val}}$ (UAC), tRNA ${ }^{\text {Ala }}$ (UGC), tRNA ${ }^{\text {Phe }}$ (GAA), tRNA ${ }^{\text {Arg }}$ (UCU), tRNA ${ }^{\text {His }}$ (GUG), tRNA ${ }^{\text {Gln }}$ (UUG), tRNA ${ }^{\text {Cys }}$ (GCA), tRNA ${ }^{\text {Lys }}$ (UUU), tRNA $^{\text {Glu }}$ (UUC), tRNA ${ }^{\text {Ile }}$ (UAU), tRNA ${ }^{\text {Val }}$ (GAC), tRNA ${ }^{\text {Leu }}$ (CAA), tRNA Gly (UCC), tRNA ${ }^{\text {Ser }}$ (CGA), tRNA ${ }^{\text {Gly }}$ (GCC), and tRNA ${ }^{\text {Ile }}$ (CAU), tended to be the most basic tRNAs and they had undergone gene duplication and diversification to generate other tRNA molecules.

\section{C-A-U anticodon in tRNA ${ }^{\text {Ile }}$}

Our detailed genomic study showed that $\mathrm{tRNA}^{\text {Ile }}$ also encodes a C-A-U anticodon in addition to the presence of this typical anticodon in $\mathrm{tRNA}^{\mathrm{Met}}$. In general, the C-A-U anticodon is recognized as a typical characteristic of tRNA ${ }^{\text {Met }}$ and there is only one iso-acceptor. In particular, we found that the tRNA ${ }^{\text {Ile }}$ in $T$. mairei encodes two C-A-U anticodons, and C. debaoensis, S. verticillata, D. spinulosum, C. lanceolata, G. biloba, C. deodara, W. mirabilis, G. gnemon, R. piresii, E. equisetina, and W. nobilis also encode a C-A-U anticodon (Table 3, Data S1, Fig. S3). 
279 Transition/transversion of tRNAs

280 A previous study (Mohanta et al., 2019) showed that the evolutionary rates are almost equal for

281 tRNAs with respect to transition and transversion despite the low probability of transition or

282 transversion events in tRNAs. In this study, we identified several intriguing substitutions of

283 gymnosperm chloroplast tRNAs. Overall, our analysis of the substitution rates detected using the

284 whole set of chloroplast tRNAs showed that average transition rate (15.38) was significantly

285 larger than the average transversion rate (4.81) with a ratio of 3:1 (Table 5). The same transition:

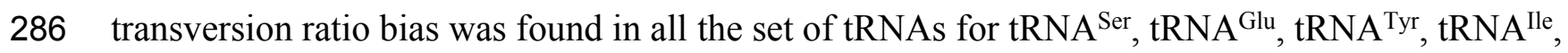
287 tRNA $^{\text {Met }}, \mathrm{tRNA}^{\mathrm{Gln}}$, $\mathrm{RNA}^{\mathrm{Thr}}$, and tRNA ${ }^{\mathrm{Leu}}$. The ratio was over 6:1 for tRNA ${ }^{\text {Cys }}$ and $\mathrm{tRNA}^{\mathrm{Arg}}$. The 288 transition rates for $\mathrm{tRNA}^{\mathrm{Trp}}$, $\mathrm{tRNA}^{\mathrm{Val}}$, and $\mathrm{tRNA} \mathrm{Gly}^{\mathrm{Gl}}$ were about 10 times higher than their 289 transversion rates. These findings suggest that $\mathrm{tRNA}^{\mathrm{Ser}}, \mathrm{tRNA}^{\mathrm{Glu}}$, $\mathrm{tRNA}^{\mathrm{Tyr}}$, $\mathrm{tRNA}^{\mathrm{Ile}}$, $\mathrm{tRNA}^{\mathrm{Met}}$, 290 tRNA $^{\text {Gln }}$, tRNA $^{\text {Thr }}$, tRNA ${ }^{\text {Leu }}$, tRNA ${ }^{\text {Cys }}$, tRNA ${ }^{A r g}$, tRNA ${ }^{\text {Trp }}$, tRNA ${ }^{\text {Val }}$ and tRNA ${ }^{\text {Gly }}$ underwent 291 transition substitutions more readily than transversion substitutions during their evolution in 292 gymnosperm chloroplast genomes. In addition, the transition rates in tRNA ${ }^{\text {Lys }}$ and tRNA ${ }^{\text {Pro }}$ were 293 about 15 times higher than their transversion rates. The transition rates in tRNA ${ }^{\text {Asn }}$, tRNA ${ }^{\text {Phe }}$, and 294 tRNA $^{\text {His }}$ were about 20 times higher than their transversion rates. These results indicate that 295 tRNAs are much more likely to have undergone transition events rather than transversion events. 296 The highest transversion rate of 12.50 was found in RNA $^{\text {Ala }}$ and the lowest transversion rate of 2970.00 in tRNA ${ }^{\text {Asp }}$ (Table 5). Correspondingly, tRNA ${ }^{\text {Ala }}$ lacks any transitions (Table 5).

298

299

tRNA duplication/loss events

300 In addition to transition and transversion events, gene duplication and loss events have played

301 important roles in gene evolution. Our analysis of duplication and loss events indicated that 153

302 duplication events (duplication and conditional duplication) have occurred in all of the

303 gymnosperm chloroplast tRNA genes investigated in this study (Fig. S2). In addition, 220

304 gymnosperm chloroplast tRNA gene loss events were detected (Table S2, Fig. S2). Thus, the loss 305 of genes was slightly more frequent than their duplication for gymnosperm chloroplast tRNA 306 genes.

307

\section{Discussion}

309 tRNAs are major genetic components of semi-autonomous chloroplasts and our analysis of 310 gymnosperm chloroplast genomes showed that they have several basic conserved genomic 311 features. The gymnosperm chloroplast genomes investigated in the present study were found to 312 encode 28 to 33 tRNA isotypes, thereby indicating that there is substantial variation in the 313 quantity of tRNAs in gymnosperm chloroplast genomes. The lack of tRNA ${ }^{\text {Ala }}$ in $R$. piresii and $T$. 314 mairei, and the absence of tRNA ${ }^{\mathrm{Val}}$ in T. mairei were interesting. Thus, it is necessary to 315 understand how the translation process is conducted in chloroplasts without these crucial tRNAs. 316 According to previous studies (Treangen \& Rocha, 2011; Mohanta et al., 2019), it is likely that 317 the deficiency of these tRNAs is compensated for by the transfer of corresponding tRNAs from 318 the nucleus or mitochondria. In addition to the absence of tRNA ${ }^{\text {Ala }}$ and tRNA ${ }^{\mathrm{Val}}$, all of the 
319 gymnosperm plants were shown to not encode selenocysteine tRNA and its suppressor tRNA in 320 their chloroplast genomes (Table 2). Selenocysteine tRNA and its suppressor tRNA were also

321

322

323

324

325

326

327

328

329

330

331

332

333

334

335

336

337

338

339

340

341

342

343

344

345

346

347

348

349

350

351

352

353

354

355

356

357

358 not detected in the chloroplast of Oryza sativa (Mohanta \& Bae, 2017).

In addition to the presence of C-A-U anticodon in tRNA ${ }^{\text {Met }}$, we found that tRNA-CAU is present in tRNA ${ }^{\text {Ile }}$ (Table 3). Similarly, the C-A-U anticodon was detected in tRNA ${ }^{\text {Ile }}$ in Bacillus subtilis (Ehrenberg) Cohn and spinach (Kashdan \& Dudock, 1982; Köhrer et al., 2014). The possible mechanism that governs the specificity of this amino acid may involve modification of the wobble position in the anticodon by a tRNA-modifying enzyme. Chloroplasts originate from bacteria so the tRNA modifications found in bacteria may also occur in chloroplast tRNAs. In bacteria, the tRNA-modifying enzyme TilS can convert the 5'-C residue in the CAU anticodon of specific tRNA ${ }^{\text {Ile }}$ molecules into lysidine to decode 5'-AUA (Ile) codons instead of 5'-AUG (Met) codons (Soma et al., 2003). In addition, when lysidine decodes isoleucine, the tautomer form of lysidine provides compatible hydrogen bond donor-acceptor sites to allow base pairing with "A" and this may help to the recognition of the codon AUA instead of AUG (Sonawane \& Tewari, 2008; Sambhare et al., 2014). The absence of tRNA ${ }^{\mathrm{Ile}}$-lysidine synthetase leads to a failure to modify C34 to lysidine in tRNA ${ }^{\mathrm{Ile}}$ (LAU) (i.e., the synthesis of CAU-tRNA ${ }^{\mathrm{Ile}}$ ) and this inactivates the translation of AUA codons (Köhrer et al., 2014).

During protein coding, a certain species or gene tends to use one or more specific synonym codons, which is referred to as codon usage bias (Comeron \& Aguadé, 1998; Rota-Stabelli et al., 2012). In the present study, tRNA ${ }^{\text {Arg-CCG }}$ was found to be present in the genomes of nine species but absent from C. lanceolata, T. mairei, and E. equisetina. Similarly, tRNA ${ }^{\text {Gly_UCC }}$ was shown to be absent from the chloroplast genomes of $C$. debaoensis, $S$. verticillata, $D$. spinulosum, C. lanceolata, T. mairei, and E. equisetina (Table 3). These results suggest that gymnosperm chloroplast tRNA genes are characterized by codon usage bias (Wei \& Jin, 2017; Li et al., 2015).

In general, the secondary structure of tRNAs is characterized as clover leaf-like, except for a few tRNAs with unusual secondary structures (Jühling et al., 2018). In our study, we identified clover leaf-like tRNAs with expanded variable loop regions (Fig. 1 and Fig. 2). Numerous tRNA ${ }^{\mathrm{Leu}}$, tRNA ${ }^{\mathrm{Ser}}$, and tRNA ${ }^{\mathrm{Tyr}}$ were found to have specific variable loop configurations in terms of length and structure, suggesting significant structural variation among chloroplast tRNAs. It is interesting to note that there were also stem-loop structures in variable regions of certain tRNAs in cyanobacteria. This might indicate that similar structural variations exist between chloroplast tRNAs and cyanobacterial tRNAs (Mohanta et al., 2017). Future studies will have to determine the biological importance of these variant tRNAs. The novel tRNA structure lacking the $\mathrm{D}$ arm might play some other significative functions in the translation progress and additional research is necessary to elucidate its exact function and mechanisms. Most tRNAs have a clover-like structure formed by complementary base pairing between small segments (Hubert et al., 1998; Florentz, 2002). Previous studies have showed that the acceptor arm of tRNAs in chloroplasts contain $7 \mathrm{bp}$ to $9 \mathrm{bp}$, the D-arm contains $3 \mathrm{bp}$ to $4 \mathrm{bp}$, the D-loop has $4 \mathrm{nt}$ to $12 \mathrm{nt}$, the anticodon arm has $5 \mathrm{bp}$, the anticodon loop contains $7 \mathrm{nt}$, the variable 
359

360

361

362

363

364

365

366

367

368

369

370

371

372

373

374

375

376

377

378

379

380

381

382

383

384

385

386

387

388

389

390

391

392

393

394

395

396

397

398

region comprises $4 \mathrm{nt}$ to $23 \mathrm{nt}$, and $\Psi$-arm contains $5 \mathrm{bp}$, and the $\Psi$-loop has $7 \mathrm{nt}$ (Wilusz, 2015; Mohanta \& Hanhong, 2017; Mohanta et al., 2019). In the present study, we found that the acceptor arm of chloroplast tRNAs contains 6 bp to 7 bp in 373 tRNAs, where the D-arm has 3 bp or $4 \mathrm{bp}$ and the D-loop usually contains $7 \mathrm{nt}$ to $11 \mathrm{nt}$. The anticodon loop of gymnosperm chloroplast tRNAs generally contains $7 \mathrm{nt}$, and thus the sequence of the anticodon loop is typically conserved (Table 4, Table S1). The variable loop of different tRNAs contain 3 nt to 23 nt (Table S1). The $\Psi$-arm of gymnosperm chloroplast tRNAs generally contains 5 bp and the $\Psi$ loop has $7 \mathrm{nt}$ (Table S1). Our results are consistent with previous findings (Wilusz, 2015; Mohanta \& Hanhong, 2017) and they suggest that chloroplast RNAs are significantly conserved. The consensus sequence "U-U-C-N-A-N ${ }_{2}$ " was found in the $\Psi$ region (Table 4). Previous studies also reported the existence of a similar sequence in the $\Psi$-loop of tRNAs in Oryza sariva and Cyanobacteria (Mohanta \& Bae, 2017; Mohanta et al., 2017). This suggests that the consensus "U-U-C-N-A-N ${ }_{2}$ " motif of the $\Psi$ region, identified here and in previous analyses, is a general consensus motif of canonical tRNAs.

Our phylogenetic analysis detected three clear clusters and many tRNA groups. Some tRNAs (tRNA ${ }^{\mathrm{Ser}}$, $\mathrm{tRNA}^{\mathrm{His}}$, and tRNA ${ }^{\mathrm{Leu}}$ ) in cluster I and cluster II were also in cluster III, thereby indicating that these tRNAs evolved from multiple lineages by gene duplication and gene divergence. Moreover, anticodon types comprising CGA, UUC, UUU, GCA, UUG, GUG, UCU, UGC, and CAU appeared several times in the phylogenetic tree, and thus the corresponding tRNAs evolved from multiple common ancestors. The overlapping of tRNAs groups demonstrates that these tRNAs might have diverse common ancestors in the evolutionary process (Mohanta \& Bae, 2017). Phylogenetic analysis also showed that tRNA Met (CAU), tRNA $^{\text {Thr }}$ (UGU, GGU), tRNA ${ }^{\text {Val }}$ (UAC), tRNA ${ }^{\text {Ala }}$ (UGC), tRNA ${ }^{\text {Phe }}$ (GAA), tRNA ${ }^{\text {Arg }}$ (UCU), tRNA $^{\text {His }}$ (GUG), tRNA $^{\text {Gln }}$ (UUG), tRNA ${ }^{\text {Cys }}$ (GCA), tRNA ${ }^{\text {Lys }}$ (UUU), tRNA ${ }^{\text {Glu }}$ (UUC), tRNA ${ }^{\text {Ile }}$ (UAU), tRNA ${ }^{\text {Val }}$ (GAC), tRNA ${ }^{\text {Leu }}(\mathrm{CAA}), \mathrm{tRNA}^{\mathrm{Gly}}$ (UCC), tRNA $^{\text {Ser }}$ (CGA), tRNA ${ }^{\text {Gly }}$ (GCC), and tRNA ${ }^{\text {Ile }}(\mathrm{CAU})$ in cluster III tended to be the most basic tRNAs, whereas tRNA ${ }^{\text {Met }}$ tended to be the most original tRNA. Overall, the results clearly indicate that the tRNAs encoded in gymnosperm chloroplast genomes have multiple common evolutionary ancestors.

Our results also provided insights into the gene substitution rates in gymnosperm chloroplast tRNAs. Overall, the average transition rate for tRNAs was greater than the transversion rate, where the relationship was about 3:1 (Table 5). In all of the chloroplast tRNAs, the average transition rate was slightly higher than the average transversion rate, thereby indicating that chloroplast tRNAs have unequal substitution rates.

In addition to the transition and transversion events in tRNAs, loss and duplication events have played significant roles in the evolution of tRNAs in gymnosperm chloroplast genomes ( $\mathrm{He}$ \& Zhang, 2006; Magadum et al., 2013). In general, the gene loss events tended to occur after whole genome duplication events. We found 153 duplication events and 220 loss events in gymnosperm chloroplast tRNAs, and thus loss events have occurred slightly more frequently than duplication events (Table S2). 


\section{Conclusions}

400 Our basic structure analysis showed that gymnosperm chloroplast genomes encode 25 to 30

401

402

403

404

405

406

407

408

409

410

411

412

413

414

415

416

417

418

419

420

421

422

423

424

425

426

427

428

429

430

431

432

433

434

435

436

anticodon-specific tRNAs. The acceptor arm of chloroplast tRNA contains $6 \mathrm{bp}$ to $7 \mathrm{bp}$, the Darm has $3 \mathrm{bp}$ or $4 \mathrm{bp}$, the D-loop contains $7 \mathrm{nt}$ to $11 \mathrm{nt}$ mainly, and the anticodon loop usually contains $7 \mathrm{nt}$. In different tRNAs, the variable loop contains $3 \mathrm{nt}$ to $23 \mathrm{nt}$. The $\Psi$-arm contains a conserved sequence comprising U-U-C-N-A-N ${ }_{2}$. RNA $^{\text {Ala }}$ was absent from $R$. piresii and $T$. mairei, and tRNA ${ }^{\mathrm{Val}}$ was lacking in T. mairei. Gymnosperm chloroplasts do not encode selenocysteine tRNA and its suppressor tRNA in their genomes. A CAU anticodon is encoded in tRNA $^{\text {Met }}$ as well as in tRNA ${ }^{\text {Ile }}$. A novel tRNA structure lacking the D arm was identified for the chloroplast tRNA ${ }^{\text {Gly }}$ of $W$. nobilis. Numerous $\mathrm{tRNA}^{\mathrm{Leu}}$, $\mathrm{tRNA}{ }^{\mathrm{Ser}}$, and $\mathrm{tRNA}^{\mathrm{Tyr}}$ types were found to have expanded variable regions. Phylogenetic analysis showed that tRNAs might have multiple common ancestors in the evolutionary process. Different tRNAs harbored their own transition/transversion rates, i.e., it was iso-acceptor specific. And the transition rate was generally higher than the transversion rate. Furthermore, gene loss events (220) have occurred slightly more frequently than gene duplication events (153) in gymnosperm chloroplast tRNAs. Our results provide new insights into the evolution of gymnosperm chloroplast tRNAs and their diverse roles.

\section{Acknowledgements}

We thank Mr. Heng Liu for his kindly help for the evolutionary analysis of chloroplast tRNA. We also thank College of Life Sciences, Northwest University for supporting device platform for this study.

\section{References}

Abdallah F, Salamini F, Leister D. 2000. A prediction of the size and evolutionary origin of the proteome of chloroplasts of Arabidopsis. Trends in plant science 5:141-142. DOI:

10.1016/S1360-1385(00)01574-0

Chen K, Durand D, Farach-Colton M. 2000. Notung: a program for dating gene duplications and optimizing gene family trees. Journal of computational biology: a journal of computational molecular cell biology 7:429-447. DOI: 10.1089/106652700750050871

Christenhusz MJM, Reveal JL, Farjon A, Gardner MF, Mill RR, Chase MW. 2010. A new classification and linear sequence of extant gymnosperms. Phytotaxa 19:55-70. DOI: 10.11646/phytotaxa.19.1.3

Civan P, Foster PG, Embley MT, Séneca A, Cox CJ. 2014. Analyses of charophyte chloroplast genomes help characterize the ancestral chloroplast genome of land plants. Genome biology and evolution 6:897-911. DOI: 10.1093/gbe/evu061

Comeron JM, AguadéM. 1998. An evaluation of measures of synonymous codon usage bias. Journal of molecular evolution 47:268-274. DOI: 10.1007/PL00006384

Peer] reviewing PDF | (2019:11:43190:4:0:NEW 5 Oct 2020) 
437

438

439

440

441

442

443

444

445

446

447

448

449

450

451

452

453

454

455

456

457

458

459

460

461

462

463

464

465

466

467

468

469

470

471

472

473

474

475

476

Crisp MD, Cook LG. 2011. Cenozoic extinctions account for the low diversity of extant gymnosperms compared with angiosperms. The New phytologist 192:997-1009. DOI:10.1111/j.1469-8137.2011.03862.x

Des Marais DJ. 2000. When did photosynthesis emerge on earth? Science 289:1703-1705. DOI:10.1126/science.289.5485.1703

Dong WL, Wang RN, Yan XH, Niu C, Gong LL, Li ZH. 2016. Characterization of polymorphic microsatellite markers in Pinus armandii (pinaceae), an endemic conifer species to China. Applications in plant sciences 4:1600072. DOI:10.3732/apps.1600072

Drouin G, Daoud H, Xia J. 2008. Relative rates of synonymous substitutions in the mitochondrial, chloroplast and nuclear genomes of seed plants. Molecular phylogenetics and evolution 49:827-831. DOI: 10.1016/j.ympev.2008.09.009

Duchene D, Bromham L. 2013. Rates of molecular evolution and diversification in plants: chloroplast substitution rates correlate with species-richness in the Proteaceae. BMC evolutionary biology 13:65. DOI: 10.1186/1471-2148-13-65

FauréS, Noyer JL, Carreel F, Horry JP, Bakry F, Lanaud C. 1994. Maternal inheritance of chloroplast genome and paternal inheritance of mitochondrial genome in bananas (Musa acuminata). Current genetics 25:265-269. DOI: 10.1007/BF00357172

Florentz C. 2002. Molecular investigations on tRNAs involved in Human mitochondrial disorders. Bioscience reports 22:81-98. DOI: 10.1023/a:1016065107165

Forest F, Moat J, Baloch E, Brummitt NA, Bachman SP, Ickert-Bond S, Hollingsworth PM, Liston A, Little DP, Mathews S, Rai H, Rydin C, Stevenson DW, Thomas P, Buerki S. 2018. Gymnosperms on the edge. Scientific reports. 8:1-11. DOI:10.1038/s41598-018-24365-4.

Gerrienne P, Meyer-Berthaud B, Fairon-Demaret M, Streel M, Steemans P. 2004. Runcaria, a middle devonian seed plant precursor. Science 306. DOI:10.1126/science.1102491

Giegé R, Puglisi JD, Florentz C. 1993. tRNA structure and aminoacylation efficiency. Progress in nucleic acid research and molecular biology 45:129-206. DOI: 10.1016/S00796603(08)60869-7

Guo SW, Zhou Y, Gao YX, Li Y, Shen QR. 2007. New insights into the nitrogen form effect on photosynthesis and photorespiration. Pedosphere 17:601-610. DOI: 10.1016/S10020160(07)60071-X

He XL, Zhang JZ. 2006. Transcriptional reprogramming and backup between duplicate genes: is it a genome wide phenomenon? Genetics 172:1363-1367. DOI: 10.1534/genetics.105.049890 Hereward JP, Werth JA, Thornby DF, Keenan M, Chauhan BS, Walter GH. 2018. Complete chloroplast genome of glyphosate resistant $\backslash r$, Sonchus oleraceus $\backslash r$, L. from Australia, with notes on the small single copy (SSC) region orientation. Mitochondrial DNA Part B. 3: 363364. DOI:10.1080/23802359.2018.1450682.

Heuertz M, Fineschi S, Anzidei M, Pastorelli R, Salvini D, Paule L, Frascaria-Lacoste N, Hardy OJ, Vekemans X, Vendramin GG. 2004. Chloroplast DNA variation and postglacial recolonization of common ash (Fraxinus excelsior L.) in Europe. Molecular ecology 13:34373452. DOI: 10.1111/j.1365-294X.2004.02333.x 
477 Hiroki I, Daisuke S. 2018. Bacterial heterologous expression system for reconstitution of

478

479

480

481

482

483

484

485

486

487

488

489

490

491

492

493

494

495

496

497

498

499

500

501

502

503

504

505

506

507

508

509

510

511

512

513

514

515 molecular sciences 19:544-556. DOI: 10.3390/ijms19020544

Hoober JK. (2006). Chloroplast Development: Whence and Whither. In: Wise RR, Hoober JK, ed. The Structure and Function of Plastids. Springer Netherlands, 27-51.

Hubert N, Sturchler C, Westhof E, Carbon P, Krol A. 1998. The 9/4 secondary structure of eukaryotic selenocysteine tRNA: more pieces of evidence. $R N A$ 4:1029-1033. DOI: $10.1017 / \mathrm{S} 1355838298980888$

Jühling T, Duchardt-Ferner E, Bonin S, Wöhnert J, Pütz J, Florentz C, Betat H, Sauter C, Mörl M. 2018. Small but large enough: structural properties of armless mitochondrial tRNAs from the nematode romanomermis culicivorax. Nucleic acids research 46:9170-9180. DOI: 10.1093/nar/gky593

Kanai A. 2015. Disrupted tRNA genes and tRNA fragments: a perspective on tRNA gene evolution. Life 5:321-331. DOI: 10.3390/life5010321

Kashdan, MA, Dudock BS. 1982. The gene for spinach chloroplast isoleucine tRNA has a methionine anticodon. The Journal of biological chemistry 257:11191-11194.

Kaundun SS, Matsumoto S. 2011. Molecular evidence for maternal inheritance of the chloroplast genome in tea, Camellia sinensis (L.) O. Kuntze. Journal of the science of food and agriculture 91:2660-2663. DOI: 10.1002/jsfa.4508

Kim S, Suh Y. 2013. Phylogeny of Magnoliaceae based on ten chloroplast DNA regions. Journal of plant biology 56:290-305. DOI: 10.1007/s12374-013-0111-9

Kirchner S, Ignatova Z. 2014. Emerging roles of tRNA in adaptive translation, signalling dynamics and disease. Nature reviews. Genetics 16:98-112. DOI: 10.1038/nrg3861

Knorr W, Heimann M. 2001. Uncertainties in global terrestrial biosphere modeling: 1. A comprehensive sensitivity analysis with a new photosynthesis and energy balance scheme. Global biogeochemical cycles 15:207-225. DOI: 10.1029/1998gb001059

Köhrer C, Mandal D, Gaston KW, Grosjean H, Limbach PA, RajBhandary UL. 2014. Life without tRNAIle-lysidine synthetase: translation of the isoleucine codon AUA in Bacillus subtilis lacking the canonical tRNA2Ile. Nucleic acids research 42:1904-1915. DOI: 10.1093/nar/gkt1009

Kretschmer M, Croll D, Kronstad JW. 2017. Chloroplast-associated metabolic functions influence the susceptibility of maize to Ustilago maydis. Molecular plant pathology 18:12101221. DOI: $10.1111 / \mathrm{mpp} .12485$

Kumar S, Nei M, Dudley J, Tamura K. 2008. MEGA: A biologist-centric software for evolutionary analysis of DNA and protein sequences. Briefings in bioinformatics 9:299-306. DOI: $10.1093 / \mathrm{bib} / \mathrm{bbn} 017$

Kumar S, Stecher G, Tamura K. 2016. MEGA7: Molecular Evolutionary Genetics Analysis version 7.0 for bigger datasets. Molecular biology 33:1870-1874. DOI:

10.1093/molbev/msw054

Peer) reviewing PDF | (2019:11:43190:4:0:NEW 5 Oct 2020) 
516 Kumar S, Tamura K, Nei M. 1994. Mega: molecular evolutionary genetics analysis software for

517

518

519

520

521

522

523

524

525

526

527

528

529

530

531

532

533

534

535

536

537

538

539

540

541

542

543

544

545

546

547

548

549

550

551

552

553

554

555

microcomputers. Computer applications in the biosciences: CABIOS 10:189-191. DOI: 10.1093/bioinformatics/10.2.189

Laslett D, Canback B. 2004. ARAGORN, a program to detect tRNA genes and tmRNA genes in nucleotide sequences. Nucleic acids research 32:11-16. DOI: 10.1093/nar/gkh152

Li J, Zhou J, Wu Y, Yang SH, Tian DC. 2015. GC-content of synonymous codons profoundly influences amino acid usage. G3: genes - genomes - genetics 5:2027-2036. DOI: 10.1534/g3.115.019877

Li ZH, Chen Y, Mao KS, Ma YZ, Liu J, Liu ZL, Deng TT, Zhao GF. 2015. Molecular identification and allopatric divergence of the white pine species in China based on the cytoplasmic DNA variation. Biochemical systematics and ecology 61:161-168. DOI: 10.1016/j.bse.2015.06.002

Liu L, Hao ZZ, Liu YY, Wei XX, Cun YZ, Wang XQ. 2014. Phylogeography of Pinus. armandii and its relatives: heterogeneous contributions of geography and climate changes to the genetic differentiation and diversification of Chinese white pines. PloS one 9:e85920. DOI: 10.1371/journal.pone.0085920

Logacheva MD, Penin AA, Valiejo-Roman CM, Antonov AS. 2009. Structure and evolution of junctions between inverted repeat and small single copy regions of chloroplast genome in noncore caryophyllales. Molecular biology 43:757-765. DOI: 10.1134/s0026893309050070

Lowe TM, Eddy SR. 1997. tRNAscan-SE: a program for improved detection of transfer RNA genes in genomic sequence. Nucleic acids research 25:955-964. DOI: 10.1093/nar/25.5.0955

Lusic H, Gustilo EM, Vendeix FA, Kaiser R, Delaney MO, Graham WD, Moye VA, Cantara WA, Agris PF, Deiters A. 2008. Synthesis and investigation of the 5-formylcytidine modified, anticodon stem and loop of the human mitochondrial tRNA ${ }^{\text {Met }}$. Nucleic acids research 36:6548-6557. DOI: 10.1093/nar/gkn703Magadum S, Banerjee U, Murugan P, Gangapur D, Ravikesavan R. 2013. Gene duplication as a major force in evolution. Journal of genetics 92:155-161. DOI: 10.1007/s12041-013-0212-8

Mizutani T, Goto C. 2000. Eukaryotic selenocysteine tRNA has the 9/4 secondary structure. FEBS letters 466:359-362. DOI: 10.1016/s0014-5793(00)01104-2

Mohanta TK, Bae H. 2017. Analyses of genomic tRNA reveal presence of novel tRNAs in Oryza sativa. Frontiers in genetics 8:90. DOI: 10.3389/fgene.2017.00090

Mohanta TK, Khan AL, Hashem A, Abd_Allah EF, Yadav D, Al-Harrasi A. 2019. Genomic and evolutionary aspects of chloroplast tRNA in monocot plants. BMC plant biology 19:39. DOI: 10.1186/s12870-018-1625-6

Mohanta TK, Syed AS, Fuad A, Hanhong B. 2017. Novel genomic and evolutionary perspective of cyanobacterial tRNAs. Frontiers in genetics 8:200. DOI: 10.3389/fgene.2017.00200 Pilon-Smits EAH, Garifullina GF, Abdel-Ghany S, Kato SI, Mihara H, Hale KL, Burkhead JL, Esaki N, Kurihara T, Pilon M. 2002. Characterization of a NifS-like chloroplast protein from Arabidopsis. Implications for its role in sulfur and selenium metabolism. Plant Physiology 130:1309-1318. DOI: 10.1104/pp.102.010280

Peer) reviewing PDF | (2019:11:43190:4:0:NEW 5 Oct 2020) 
556 Ran JH, Gao H, Wang XQ. 2010. Fast evolution of the retroprocessed mitochondrial rps3 gene
557 in Conifer II and further evidence for the phylogeny of gymnosperms. Molecular

557

558

559

560

561

562

563

564

565

566

567

568

569

570

571

572

573

574

575

576

577

578

579

580

581

582

583

584

585

586

587

588

589

590

591

592

593

594

595 phylogenetics and evolution 54:136-149. DOI: 10.1016/j.ympev.2009.09.011

Ribasd PL, Dedon PC. 2014. More than an adaptor molecule: the emerging role of tRNA in cell signaling and disease. FEBS letters 588:4267. DOI: 10.1016/j.febslet.2014.10.022

Rota-Stabelli O, Lartillot N, Philippe H, Pisani D. 2012. Serine Codon-Usage Bias in Deep Phylogenomics: Pancrustacean Relationships as a Case Study. Systems biology 62:121-133. DOI: 10.1093/sysbio/sys077

Sambhare SB, Kumbhar BV, Kamble AD, Bavi RS, Kumbhar NM, Sonawane KD. 2014. Structural significance of modified nucleosides $\mathrm{k}^{2} \mathrm{C}$ and $\mathrm{t}^{6} \mathrm{~A}$ present in the anticodon loop of tRNA ${ }^{\text {Ile }}$. RSC advances 4:14176-14188. DOI: 10.1039/c3ra47335j

Schimmel P. 2017. The emerging complexity of the tRNA world: mammalian tRNA beyond protein synthesis. Nature reviews. Molecular cell biology 19:45-58. DOI: 10.1038/nrm.2017.77

Soma A, Ikeuchi Y, Kanemasa S, Kobayashi K, Ogasawara N, Ote T, Kato J, Watanabe K, Sekine Y, Suzuki T. 2003. An RNA-modifying enzyme that governs both the codon and amino acid specificities of isoleucine tRNA. Molecular cell 12:689-698. DOI: 10.1016/s10972765(03)00346-0

Sonawane KD, Tewari R. 2008. Conformational preferences of hypermodified nucleoside lysidine $\left(\mathrm{k}^{2} \mathrm{C}\right)$ occurring at "wobble" position in anticodon loop of tRNA ${ }^{\mathrm{Ile}}$. Nucleosides, Nucleotides and Nucleic Acids 27:1158-1174. DOI: 10.1080/15257770802341475

Suzuki T, Suzuki T. 2014. A complete landscape of post-transcriptional modifications in mammalian mitochondrial tRNAs. Nucleic acids research 42:7346-7357. DOI: 10.1093/nar/gku390

Tillich M, Lehwark P, Pellizzer T, Ulbricht-Jones ES, Fischer A, Bock R, Greiner S. 2017. GeSeq-versatile and accurate annotation of organelle genomes. Nucleic acids research 45:W6W11. DOI: $10.1093 / \mathrm{nar} / \mathrm{gkx} 391$

Treangen TJ, Rocha, EPC. 2011. Horizontal transfer, not duplication, drives the expansion of protein families in prokaryotes. PLoS genetics 7:e1001284. DOI:

10.1371/journal.pgen.1001284

Wang RJ, Cheng CL, Chang CC, Wu CL, Su TM, Chaw SM. 2008. Dynamics and evolution of the inverted repeat-large single copy junctions in the chloroplast genomes of monocots. $B M C$ evolutionary biology 8:36. DOI: 10.1186/1471-2148-8-36

Wang XQ, Ran JH. 2014. Evolution and biogeography of gymnosperms. Molecular phylogenetics and evolution 75:24-40. DOI: 10.1016/j.ympev.2014.02.005

Wei QK, Jin HY. 2017. The complete chloroplast genome sequence of Morus cathayana and Morus multicaulis, and comparative analysis within genus Morus L. Peer J 5:e3037. DOI: 10.7717/peerj.3037

Wilusz JE. 2015. Controlling translation via modulation of tRNA levels. Wiley interdisciplinary reviews. RNA 6:453-470. DOI: 10.1002/wrna.1287

Peer) reviewing PDF | (2019:11:43190:4:0:NEW 5 Oct 2020) 
596

597

598

599

600

601

602

603

604

605

606

607

608

609

610

611

612

613

614

615

616

617

618

619

620

621

622

623

624

625

626

627

628

629

630

631

632

633

634

635

Yu F, Wang DX, Yi XF, Shi XX, Huang YK, Zhang HW, Zhang XP. 2014. Does animalmediated seed dispersal facilitate the formation of Pinus armandii-quercus aliena var. acuteserrata forests? PloS one 9:e89886. DOI: 10.1371/journal.pone.0089886

Figure Legends

Fig. 1 Certain tRNAs in C. debaoensis, D. spinulosum, G. biloba, C. deodara, and R. piresii contain expanded variable stem and loops. tRNA ${ }^{\text {Ser }}$, tRNA ${ }^{\mathrm{Leu}}$, and $\mathrm{tRNA}^{\mathrm{Tyr}}$ from $C$. debaoensis, D. spinulosum, G. biloba, C. deodara, R. piresii were observed to contain an expanded variable stem and loop. The anti-codon loop of tRNA ${ }^{\mathrm{Ser}}$ (except for tRNA ${ }^{\mathrm{Ser}-G C U}$ of $D$. spinulosum) was made up of seven nucleotides with the conservative N-U-N-G-A-A-N consensus sequence, and tRNA ${ }^{\text {Leu }}$ harbor the consensus sequence C-U-N-A-N $2-A$.

Fig. 2 Certain tRNAs in S. verticillata, C. lanceolata, T. mairei, W. mirabilis, and G. gnemon contain expanded variable stem and loops. tRNA ${ }^{\mathrm{Ser}}$, tRNA ${ }^{\mathrm{Leu}}$, and $\mathrm{tRNA}^{\mathrm{Tyr}}$ from $S$. verticillata, C. lanceolata, T. mairei, W. mirabilis, G. gnemon were observed to contain a variable stem and loop. The anti-codon loop of $\mathrm{tRNA}^{\mathrm{Ser}}$ was made up of seven nucleotides with the conservative $\mathrm{N}$ U-N-G-A-A-N consensus sequence, and the consensus sequence was C-U-N-A-N $2-A$ for tRNA ${ }^{\text {Leu }}$.

Fig. 3 An abnormal tRNA structure lacking the D-arm found in W. nobilis. The tRNA ${ }^{\text {Gly }}$ with anti-codon UCC was found lacking D-arm.

Fig. 4 Clover leaf-like structure of gymnosperms tRNA. The tRNA contains the Acceptor arm (6-7 bp, dark green, $>96 \%$ conserved), D-arm (3-4 bp, light blue, $>65 \%$ conserved), D-loop (7$11 \mathrm{nt}$, purple, $>80 \%$ conserved), Anti-codon arm ( $5 \mathrm{bp}$, dark blue, $>75 \%$ conserved), anti-codon loop ( $7 \mathrm{nt}$, gray, $>99 \%$ conserved), variable region ( $3-23 \mathrm{nt}$, orange, $>45 \%$ conserved), $\Psi$-arm ( 5 bp, light purple, $>97 \%$ conserved), and $\Psi$-loop ( $7 \mathrm{nt}$, green, $>95 \%$ conserved). "\% conservation" means the conservative ratio of base identities in each stem and loop structure of the whole set of gymnosperm tRNAs. Several tRNAs harbor the nucleotides of C-C-A tail.

\section{Supplementary materials}

Data S1 tRNA sequences of gymnosperms chloroplast genome conducted in the study. Table S1 Nucleotide composition in different parts of clover-structure of chloroplast genome tRNA. AC-arm, Acceptor arm; ANC-arm, Anti-codon arm; ANC-loop, Anti-codon loop; $\Psi$-arm, Pseudouridine arm; $\Psi$-loop, Pseudouridine loop. The base pairs in the AC-arm were counted according to the predicted clover structures of tRNAs.

Table S2 Loss events of chloroplast genomic tRNAs.

Fig. S1 The phylogenetic tree constructed by 373 tRNAs. Multiple tRNAs are shown by different colors. Different groups are marked by different strings. The phylogenetic clades with low bootstrap replicates were collapsed with 50\% cutoff values. Phylogenetic analysis illustrates that Gymnosperm chloroplast tRNA derived from common multiple ancestors. 
636 Fig. S2 The loss and duplication tree. Blue: Duplication events; Gray: Loss events; D:

637 Duplication node; cD: Conditional Duplication node.

638 Fig. S3 tRNA gene content in analyzed gymnosperms chloroplast genome. The tRNA genes are 639 shown in the left (top to bottom). Boxes in light green, dark green, and white represent one 640 copy of tRNA genes, two copies of tRNA genes, and the absence of tRNA genes. 


\section{Figure 1}

Certain tRNAs in C. debaoensis, D. spinulosum, G. biloba, C. deodara, and R. piresii contain expanded variable stem and loops.

tRNA $^{\text {Ser }}$, tRNA ${ }^{\text {Leu }}$, and tRNA $A^{\text {Tyr }}$ from C. debaoensis, D. spinulosum, G. biloba, C. deodara, $R$. piresii were observed to contain an expanded variable stem and loop. The anti-codon loop of

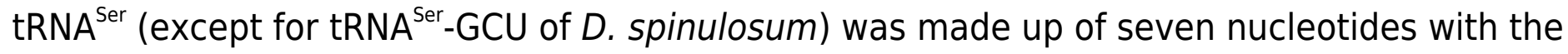
conservative N-U-N-G-A-A-N consensus sequence, and tRNA ${ }^{\text {Leu }}$ harbor the consensus sequence C-U-N-A-N2-A.
A C.debaoensis tRNA ${ }^{\text {Ser-GGA }}$
B D. spinulosum tRNA $^{\mathrm{Ser}}-\mathrm{GCU}$

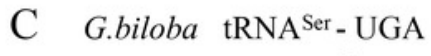
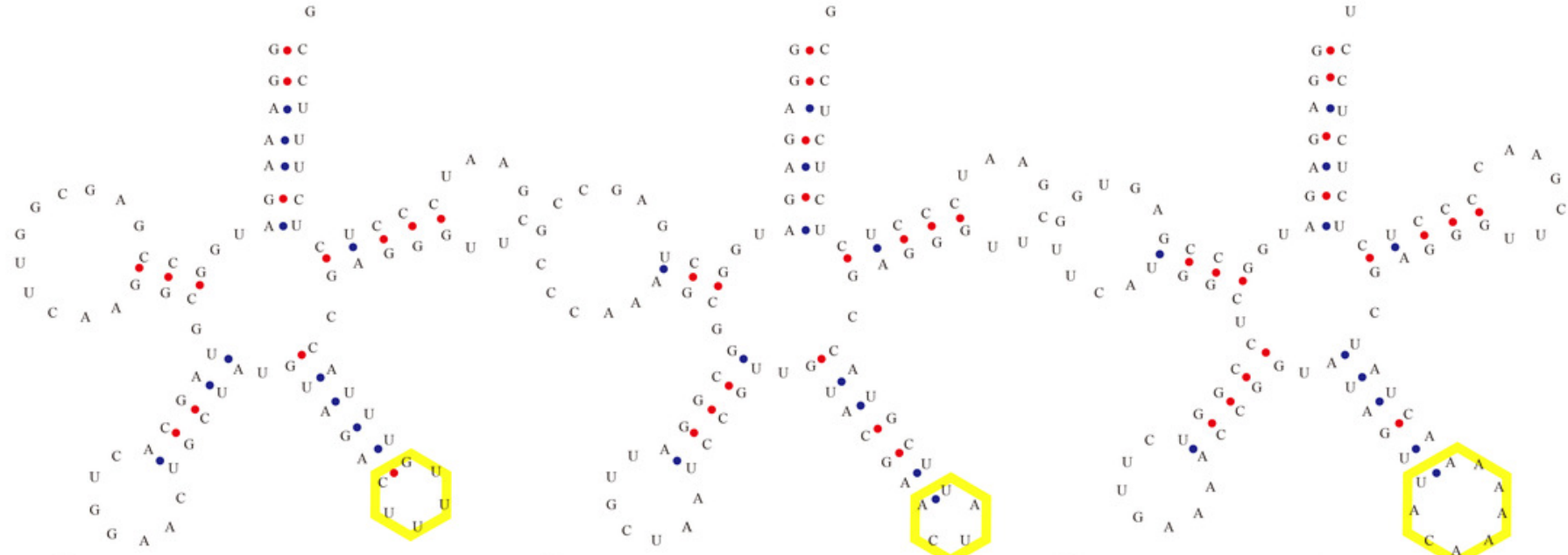

D C. deodara tRNA ${ }^{\mathrm{Ser}}-\mathrm{GGA}$

E C. deodara tRNA ${ }^{\text {Leu }}$ - CAA

F R. piresii tRNA ${ }^{\text {Tyr- GUA }}$
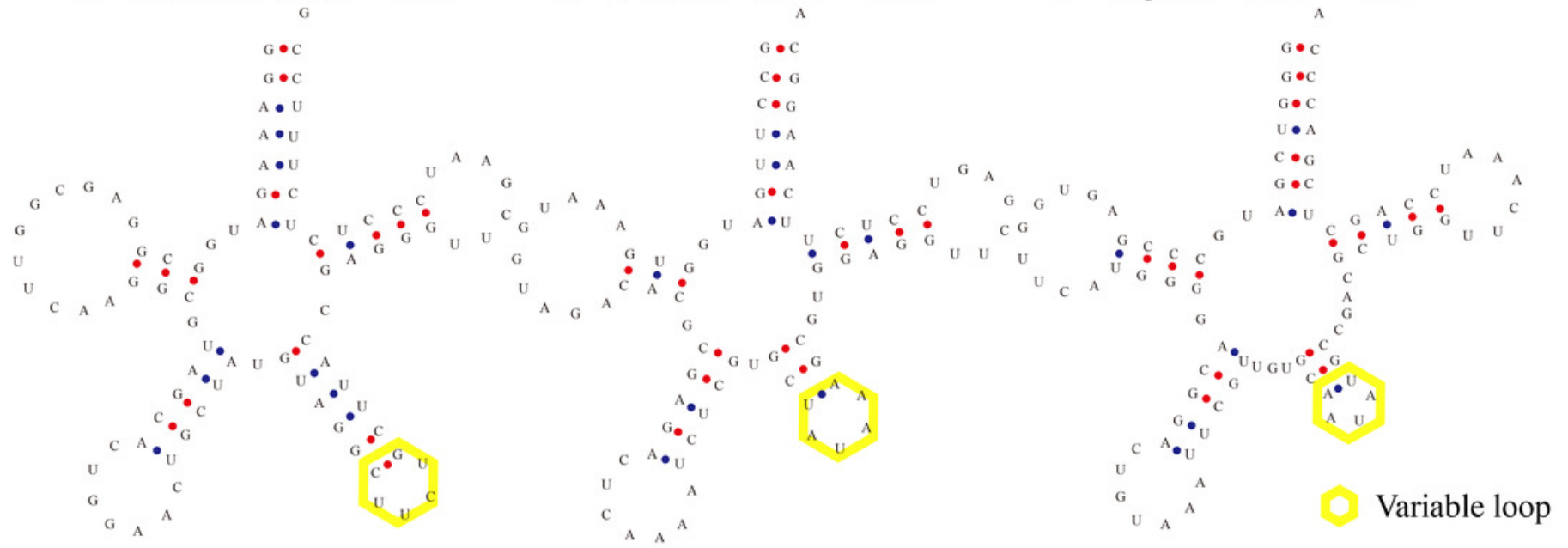


\section{Figure 2}

Certain tRNAs in S. verticillata, C. lanceolata, T. mairei, W. mirabilis, and G. gnemon contain expanded variable stem and loops.

tRNA $^{\text {Ser }}$, tRNA ${ }^{\text {Leu }}$, and tRNA ${ }^{\text {Tyr }}$ from S. verticillata, C. lanceolata, T. mairei, W. mirabilis, G. gnemon were observed to contain a variable stem and loop. The anti-codon loop of tRNA ${ }^{\text {Ser }}$ was made up of seven nucleotides with the conservative N-U-N-G-A-A-N consensus sequence, and the consensus sequence was C-U-N-A-N2-A for tRNA ${ }^{\text {Leu }}$.

A S. verticillata $\mathrm{tRNA}^{\mathrm{Ser}}-\mathrm{UGA}$

B C. lanceolata $\mathrm{TRNA}^{\mathrm{Leu}}$ - UAA

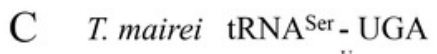

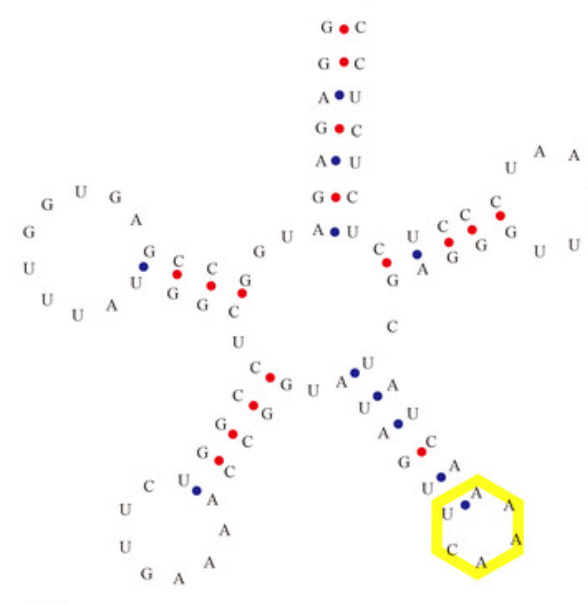

D W. mirabilis tRNA $^{\text {Ser-GGA }}$
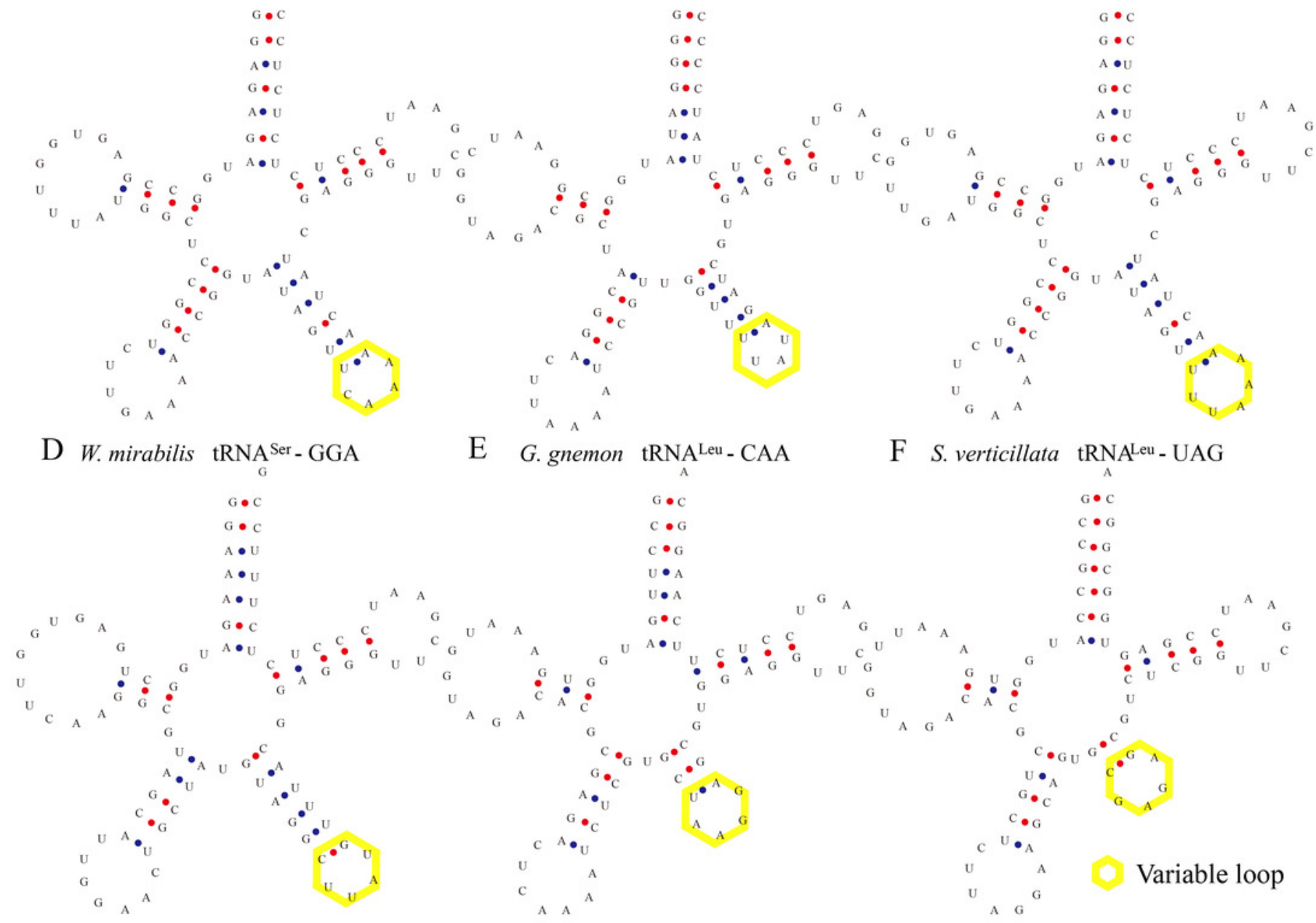

E G. gnemon tRNA ${ }^{\mathrm{Leu}}-\mathrm{CAA}$

F S. verticillata tRNA $\mathrm{L}^{\mathrm{Leu}}-\mathrm{UAG}$

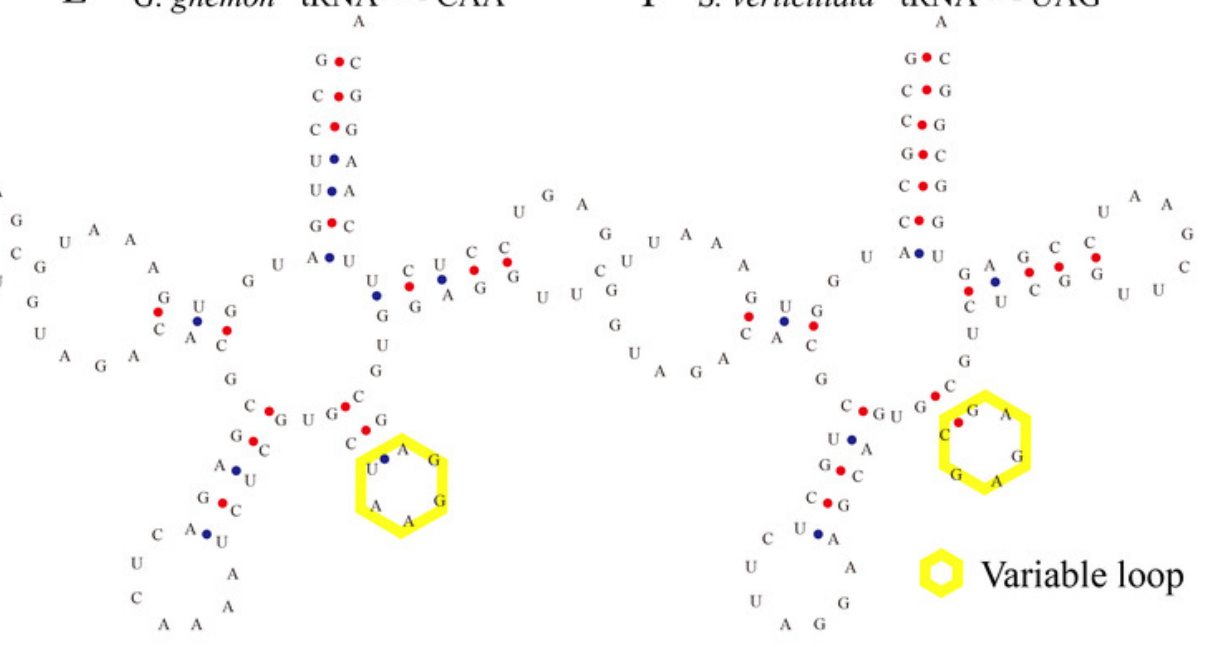


Figure 3

An abnormal tRNA structure lacking the D-arm found in W. nobilis.

The tRNA ${ }^{\text {Gly }}$ with anti-codon UCC was found lacking D-arm. 


\section{W. nobilis tRNA ${ }^{\text {Gly }}-\mathrm{UCC}$ \\ U}

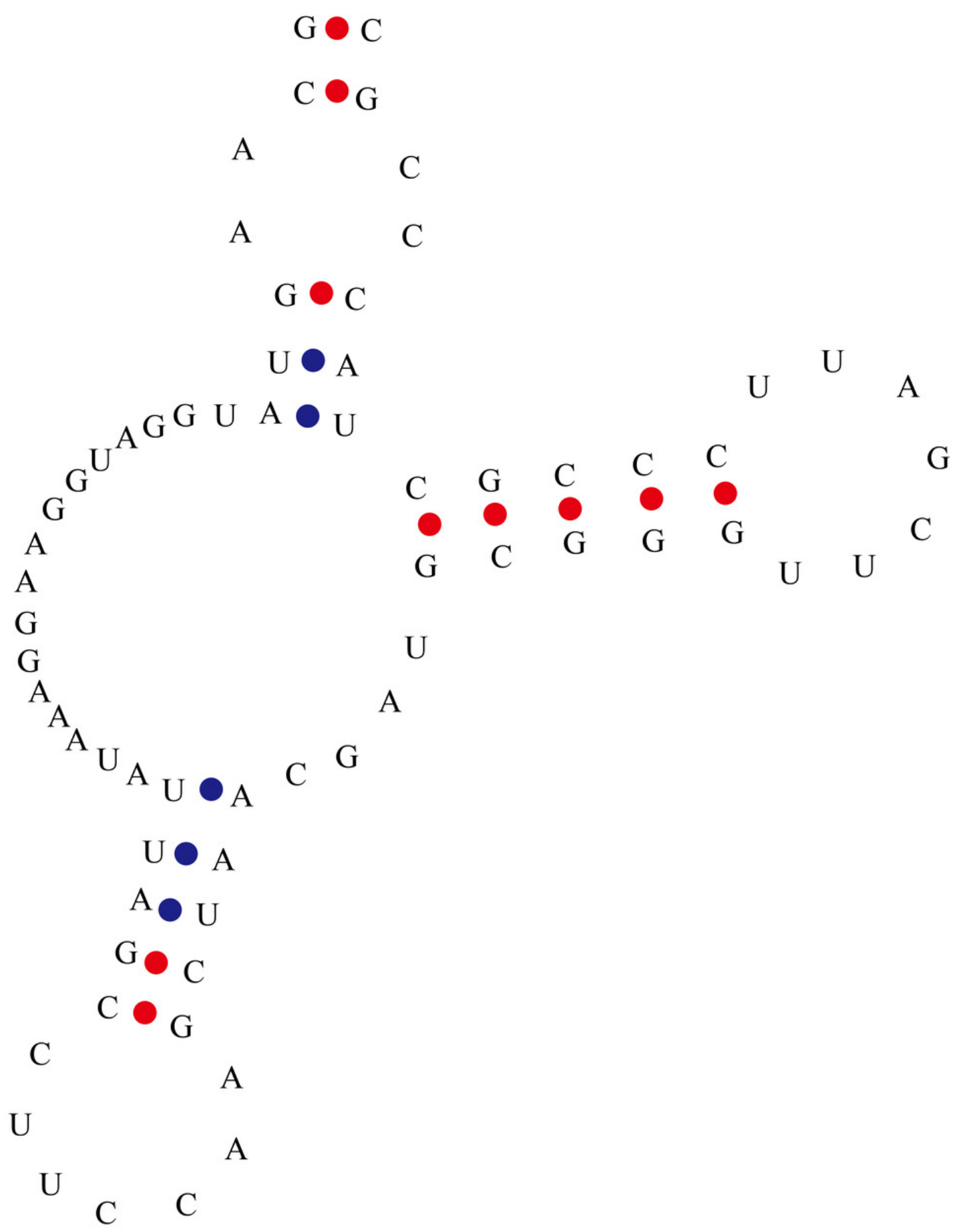




\section{Figure 4}

Clover leaf-like structure of gymnosperms tRNA.

The tRNA contains the Acceptor arm (6-7 bp, dark green, >96\% conserved), D-arm (3-4 bp, light blue, $>65 \%$ conserved), D-loop (7-11 nt, purple, $>80 \%$ conserved), Anti-codon arm (5 bp, dark blue, $>75 \%$ conserved), anti-codon loop ( $7 \mathrm{nt}$, gray, $>99 \%$ conserved), variable region (3-23 nt, orange, $>45 \%$ conserved), $\psi$-arm ( $5 \mathrm{bp}$, light purple, $>97 \%$ conserved), and $\psi$-loop ( $7 \mathrm{nt}$, green, $>95 \%$ conserved). "\% conservation" means the conservative ratio of base identities in each stem and loop structure of the whole set of gymnosperm tRNAs. Several tRNAs harbor the nucleotides of C-C-A tail. 


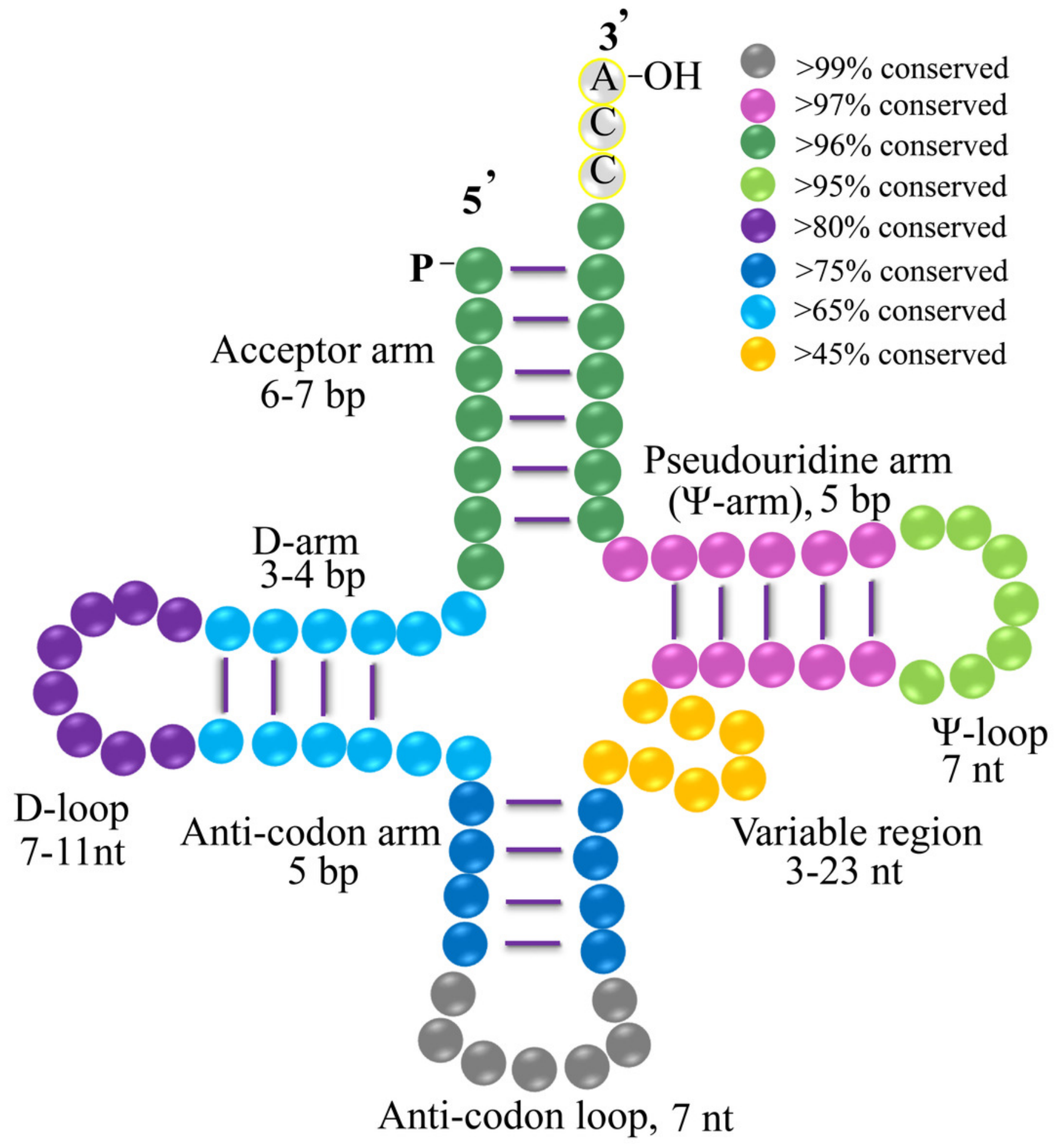




\section{Table $\mathbf{1}$ (on next page)}

A view of the gymnosperms in analysis.

Statistics of the 12 gymnosperms in the study. 
1 Table 1. A view of the gymnosperms in analysis.

\begin{tabular}{cccccc}
\hline Order & Family & Subfamily & Genus & Species & NCBI Locus \\
\hline Cycadales & Cycadaceae & & Cycas & debaoensis & KM459003 \\
& Zamiaceae & Diooideae & Dioon & spinulosum & NC_027512 \\
Ginkgoales & Ginkgoaceae & & Ginkgo & biloba & NC_016986 \\
Pinales & Pinaceae & Abieteae & Cedrus & deodara & NC_014575 \\
Araucariales & Araucariaceae & & Wollemia & nobilis & NC_027235 \\
& Podocarpaceae & & Retrophyllum & piresii & KJ017081 \\
Cupressales & Sciadopityaceae & & Sciadopitys & verticillata & NC_029734 \\
& Cupressaceae & Cunninghami & Cunninghamia & lanceolata & NC_021437 \\
& Taxaceae & a & Taxus & mairei & KJ123824 \\
Welwitschiales & Welwitschiaceae & & Welwitschia & mirabilis & EU342371 \\
Gnetales & Gnetaceae & & Gnetum & gnemon & KR476377 \\
Ephedrales & Ephedraceae & & Ephedra & equisetina & NC_011954 \\
\hline
\end{tabular}

2 


\section{Table 2 (on next page)}

Distribution of tRNA isotypes in chloroplast genome of gymnosperms.

There are 28 to 33 tRNA isotypes distributed in chloroplast genome of gymnosperms. 
Table 2. Distribution of tRNA isotypes in chloroplast genome of gymnosperms.

\begin{tabular}{|c|c|c|c|c|c|c|c|c|c|c|c|c|}
\hline \multirow{2}{*}{$\begin{array}{l}\text { tRNA } \\
\text { Isotypes }\end{array}$} & \multicolumn{12}{|c|}{ Number of tRNAs } \\
\hline & $\begin{array}{c}C . \\
\text { debaoensis } \\
\end{array}$ & $\begin{array}{c}D . \\
\text { spinulosum }\end{array}$ & $\begin{array}{c}\text { G. } \\
\text { biloba }\end{array}$ & $\begin{array}{c}C . \\
\text { deodara }\end{array}$ & $\begin{array}{c}\text { W. } \\
\text { nobilis }\end{array}$ & $\begin{array}{c}R . \\
\text { piresii } \\
\end{array}$ & $\begin{array}{c}S . \\
\text { verticillata } \\
\end{array}$ & $\begin{array}{c}C . \\
\text { lanceolata }\end{array}$ & $\begin{array}{c}T . \\
\text { mairei }\end{array}$ & $\begin{array}{c}W . \\
\text { mirabilis }\end{array}$ & $\begin{array}{c}\text { G. } \\
\text { gnemon }\end{array}$ & $\begin{array}{c}E . \\
\text { equisetina }\end{array}$ \\
\hline Ala & 1 & 1 & 1 & 1 & 1 & 0 & 1 & 1 & 0 & 1 & 1 & 1 \\
\hline Gly & 1 & 1 & 2 & 2 & 2 & 2 & 1 & 1 & 1 & 2 & 2 & 1 \\
\hline Pro & 2 & 2 & 2 & 2 & 2 & 2 & 1 & 2 & 2 & 2 & 2 & 1 \\
\hline Thr & 1 & 2 & 2 & 2 & 2 & 2 & 2 & 2 & 2 & 2 & 2 & 1 \\
\hline Val & 2 & 2 & 1 & 1 & 1 & 2 & 2 & 2 & 0 & 2 & 2 & 1 \\
\hline Ser & 3 & 3 & 3 & 3 & 4 & 3 & 3 & 3 & 2 & 3 & 3 & 3 \\
\hline Arg & 3 & 3 & 3 & 3 & 3 & 3 & 3 & 2 & 2 & 4 & 3 & 2 \\
\hline Leu & 3 & 3 & 3 & 3 & 3 & 3 & 3 & 3 & 3 & 3 & 3 & 3 \\
\hline Phe & 1 & 1 & 1 & 1 & 1 & 1 & 1 & 1 & 1 & 1 & 1 & 1 \\
\hline Asn & 1 & 1 & 1 & 1 & 1 & 1 & 1 & 1 & 1 & 1 & 1 & 1 \\
\hline Lys & 1 & 1 & 1 & 1 & 1 & 1 & 1 & 2 & 1 & 1 & 1 & 1 \\
\hline Asp & 1 & 1 & 1 & 1 & 1 & 2 & 1 & 1 & 1 & 1 & 1 & 1 \\
\hline Glu & 2 & 2 & 1 & 2 & 2 & 2 & 2 & 2 & 1 & 2 & 2 & 2 \\
\hline His & 1 & 1 & 2 & 1 & 1 & 1 & 1 & 1 & 1 & 1 & 1 & 1 \\
\hline Gln & 1 & 1 & 1 & 1 & 1 & 1 & 2 & 2 & 1 & 1 & 1 & 1 \\
\hline Ile & 1 & 1 & 1 & 1 & 1 & 1 & 1 & 1 & 4 & 1 & 1 & 1 \\
\hline Met/fMet & 2 & 2 & 2 & 2 & 2 & 2 & 2 & 2 & 2 & 2 & 2 & 2 \\
\hline Tyr & 1 & 1 & 2 & 1 & 1 & 1 & 1 & 1 & 1 & 1 & 1 & 1 \\
\hline Cys & 1 & 1 & 2 & 1 & 1 & 1 & 1 & 1 & 1 & 1 & 1 & 1 \\
\hline $\operatorname{Trp}$ & 1 & 1 & 1 & 1 & 1 & 1 & 1 & 1 & 1 & 1 & 1 & 2 \\
\hline $\begin{array}{c}\text { Selenocystei } \\
\text { ne }\end{array}$ & 0 & 0 & 0 & 0 & 0 & 0 & 0 & 0 & 0 & 0 & 0 & 0 \\
\hline Suppressor & 0 & 0 & 0 & 0 & 0 & 0 & 0 & 0 & 0 & 0 & 0 & 0 \\
\hline Total & 30 & 31 & 33 & 31 & 32 & 32 & 31 & 32 & 28 & 33 & 32 & 28 \\
\hline
\end{tabular}




\section{Table 3 (on next page)}

Distribution of anti-codons in the chloroplast genome of gymnosperms.

Each of the gymnosperm chloroplast genomes encodes 25 to 30 anticodon-specific tRNAs. $E$. equisetina encodes 25 anticodons, T. mairei encodes 26 anticodons, $C$. debaoensis, $S$. verticillata, and C. lanceolata encode 28 anticodons, and D. spinulosum, C. deodara, W. mirabilis, and R. piresii encode 29 anticodons. Other species comprising W. nobilis, $G$. gnemon and $G$. biloba encodes 30 anticodons. 
1 Table 3. Distribution of anti-codons in the chloroplast genome of gymnosperms.

\begin{tabular}{|c|c|c|c|c|c|c|c|c|c|c|c|c|c|}
\hline $\begin{array}{c}\text { tRNA } \\
\text { Isotypes }\end{array}$ & \multicolumn{6}{|c|}{ Isoacceptors } & tRNA Isotypes & \multicolumn{6}{|c|}{ Isoacceptors } \\
\hline & \multicolumn{6}{|c|}{ C. debaoensis (28) } & \multicolumn{7}{|c|}{ S. verticillata (28) } \\
\hline Ala & AGC: 0 & GGC: 0 & CGC: 0 & UGC: 1 & & & Ala & AGC: 0 & GGC: 0 & CGC: 0 & UGC: 1 & & \\
\hline Gly & ACC: 0 & GCC: 1 & CCC: 0 & UCC: 0 & & & Gly & ACC: 0 & GCC: 1 & CCC: 0 & UCC: 0 & & \\
\hline Pro & AGG: 0 & GGG: 1 & CGG: 0 & UGG: 1 & & & Pro & AGG: 0 & GGG: 0 & CGG: 0 & UGG: 1 & & \\
\hline Thr & AGU: 0 & GGU: 0 & CGU: 0 & UGU: 1 & & & Thr & $\begin{array}{c}\text { AGU: } \\
0\end{array}$ & $\begin{array}{c}\text { GGU: } \\
1\end{array}$ & CGU: 0 & UGU: 1 & & \\
\hline Val & AAC: 0 & GAC: 1 & CAC: 0 & UAC: 1 & & & Val & AAC: 0 & GAC: 1 & CAC: 0 & UAC: 1 & & \\
\hline Ser & AGA: 0 & GGA: 1 & CGA: 0 & UGA: 1 & ACU: 0 & GCU: 1 & Ser & AGA: 0 & GGA: 1 & CGA: 0 & UGA: 1 & ACU: 0 & GCU: 1 \\
\hline Arg & ACG: 1 & GCG: 0 & CCG:1 & UCG: 0 & CCU: 0 & UCU: 1 & Arg & ACG: 1 & GCG: 0 & CCG:1 & UCG: 0 & CCU: 0 & UCU: 1 \\
\hline Leu & AAG: 0 & GAG: 0 & CAG: 0 & UAG: 1 & CAA: 1 & UAA: 1 & Leu & AAG: 0 & GAG: 0 & CAG: 0 & UAG: 1 & CAA: 1 & UAA: 1 \\
\hline Phe & AAA: 0 & GAA: 1 & & & & & Phe & $\begin{array}{c}\text { AAA: } \\
0\end{array}$ & GAA: 1 & & & & \\
\hline Asn & AUU: 0 & GUU: 1 & & & & & Asn & $\begin{array}{c}\text { AUU: } \\
0\end{array}$ & $\begin{array}{c}\text { GUU: } \\
1\end{array}$ & & & & \\
\hline Lys & CUU: 0 & UUU: 1 & & & & & Lys & $\begin{array}{c}\text { CUU: } \\
0\end{array}$ & $\begin{array}{c}\text { UUU: } \\
1\end{array}$ & & & & \\
\hline Asp & AUC: 0 & GUC: 1 & & & & & Asp & AUC: 0 & GUC: 1 & & & & \\
\hline Glu & CUC: 0 & UUC: 2 & & & & & Glu & CUC: 0 & $\begin{array}{c}\text { UUC: } \\
2\end{array}$ & & & & \\
\hline His & AUG: 0 & GUG: 1 & & & & & His & $\begin{array}{c}\text { AUG: } \\
0\end{array}$ & $\begin{array}{c}\text { GUG: } \\
1\end{array}$ & & & & \\
\hline Gln & CUG: 0 & UUG: 1 & & & & & Gln & CUG: 0 & $\begin{array}{l}\text { UUG: } \\
2\end{array}$ & & & & \\
\hline Ile & AAU: 0 & GAU: 0 & CAU: 1 & UAU: 0 & & & Ile & $\begin{array}{c}\text { AAU: } \\
0\end{array}$ & $\begin{array}{c}\text { GAU: } \\
0\end{array}$ & CAU: 1 & UAU: 0 & & \\
\hline Met & CAU: 2 & & & & & & Met & CAU: 2 & & & & & \\
\hline Tyr & AUA: 0 & GUA: 1 & & & & & Tyr & $\begin{array}{c}\text { AUA: } \\
0\end{array}$ & $\begin{array}{c}\text { GUA: } \\
1\end{array}$ & & & & \\
\hline Cys & ACA: 0 & GCA: 1 & & & & & Cys & ACA: 0 & GCA: 1 & & & & \\
\hline Trp & CCA: 1 & & & & & & $\operatorname{Trp}$ & CCA: 1 & & & & & \\
\hline Supressor & CUA: 0 & UUA: 0 & UCA: 0 & & & & Supressor & CUA: 0 & $\begin{array}{l}\text { UUA: } \\
0\end{array}$ & UCA: 0 & & & \\
\hline $\mathrm{Sec}$ & UCA: 0 & & & & & & $\mathrm{Sec}$ & UCA: 0 & & & & & \\
\hline
\end{tabular}




\begin{tabular}{|c|c|c|c|c|c|c|c|c|c|c|c|c|c|}
\hline \multicolumn{7}{|c|}{ D. spinulosum (29) } & \multicolumn{7}{|c|}{ C. lanceolata (28) } \\
\hline Ala & AGC: 0 & GGC: 0 & CGC: 0 & UGC: 1 & & & Ala & AGC: 0 & GGC: 0 & CGC: 0 & UGC: 1 & & \\
\hline Gly & ACC: 0 & GCC: 1 & CCC: 0 & UCC: 0 & & & Gly & ACC: 0 & GCC: 1 & CCC: 0 & UCC: 0 & & \\
\hline Pro & AGG: 0 & GGG: 1 & CGG: 0 & UGG: 1 & & & Pro & AGG: 0 & GGG: 1 & CGG: 0 & UGG: 1 & & \\
\hline Thr & AGU: 0 & GGU: 1 & CGU: 0 & UGU: 1 & & & Thr & $\begin{array}{c}\text { AGU: } \\
0\end{array}$ & GGU: 1 & CGU: 0 & UGU: 1 & & \\
\hline Val & AAC: 0 & GAC: 1 & CAC: 0 & UAC: 1 & & & Val & AAC: 0 & GAC: 1 & CAC: 0 & UAC: 1 & & \\
\hline Ser & AGA: 0 & GGA: 1 & CGA: 0 & UGA: 1 & ACU: 0 & GCU: 1 & Ser & AGA: 0 & GGA: 1 & CGA: 0 & UGA: 1 & ACU: 0 & GCU: 1 \\
\hline $\operatorname{Arg}$ & ACG: 1 & GCG: 0 & CCG:1 & UCG: 0 & CCU: 0 & UCU: 1 & $\operatorname{Arg}$ & ACG: 1 & GCG: 0 & CCG: 0 & UCG: 0 & CCU: 0 & UCU: 1 \\
\hline Leu & AAG: 0 & GAG: 0 & CAG: 0 & UAG: 1 & CAA: 1 & UAA: 1 & Leu & AAG: 0 & GAG: 0 & CAG: 0 & UAG: 1 & CAA: 1 & UAA: 1 \\
\hline Phe & AAA: 0 & GAA: 1 & & & & & Phe & $\begin{array}{c}\text { AAA: } \\
0\end{array}$ & GAA: 1 & & & & \\
\hline Asn & AUU: 0 & GUU: 1 & & & & & Asn & $\begin{array}{c}\text { AUU: } \\
0\end{array}$ & GUU: 1 & & & & \\
\hline Lys & CUU: 0 & UUU: 1 & & & & & Lys & $\begin{array}{c}\text { CUU: } \\
1\end{array}$ & UUU: 1 & & & & \\
\hline Asp & AUC: 0 & GUC: 1 & & & & & Asp & AUC: 0 & GUC: 1 & & & & \\
\hline Glu & CUC: 0 & UUC: 2 & & & & & Glu & CUC: 0 & UUC: 2 & & & & \\
\hline His & AUG: 0 & GUG: 2 & & & & & His & $\begin{array}{c}\text { AUG: } \\
0\end{array}$ & GUG: 1 & & & & \\
\hline Gln & CUG: 0 & UUG: 1 & & & & & Gln & CUG: 0 & UUG: 2 & & & & \\
\hline Ile & AAU: 0 & GAU: 0 & CAU: 1 & UAU: 0 & & & Ile & $\begin{array}{c}\text { AAU: } \\
0\end{array}$ & GAU: 0 & CAU: 1 & UAU: 0 & & \\
\hline Met & CAU: 2 & & & & & & Met & CAU: 2 & & & & & \\
\hline Tyr & AUA: 0 & GUA: 1 & & & & & Tyr & $\begin{array}{c}\text { AUA: } \\
0\end{array}$ & GUA: 1 & & & & \\
\hline Cys & ACA: 0 & GCA: 1 & & & & & Cys & ACA: 0 & GCA: 1 & & & & \\
\hline Trp & CCA: 1 & & & & & & Trp & CCA: 1 & & & & & \\
\hline Supressor & CUA: 0 & UUA: 0 & UCA: 0 & & & & $\begin{array}{c}\text { Supresso } \\
\mathrm{r}\end{array}$ & CUA: 0 & UUA: 0 & UCA: 0 & & & \\
\hline $\mathrm{Sec}$ & UCA: 0 & & & & & & $\mathrm{Sec}$ & UCA: 0 & & & & & \\
\hline & & G. bilo & $a \quad(3 \underline{01} 1$ & & & & & & & airei ( & & & \\
\hline Ala & AGC: 0 & GGC: 0 & CGC: 0 & UGC: 1 & & & Ala & AGC: 0 & GGC: 0 & CGC: 0 & UGC: 0 & & \\
\hline Gly & ACC: 0 & GCC: 1 & CCC: 0 & UCC: 1 & & & Gly & ACC: 0 & GCC: 1 & CCC: 0 & UCC: 0 & & \\
\hline Pro & AGG: 0 & GGG: 1 & CGG: 0 & UGG: 1 & & & Pro & AGG: 0 & GGG: 1 & CGG: 0 & UGG: 1 & & \\
\hline
\end{tabular}




\begin{tabular}{|c|c|c|c|c|c|c|c|c|c|c|c|c|c|}
\hline Thr & AGU: 0 & GGU: 1 & CGU: 0 & UGU: 1 & & & Thr & $\begin{array}{c}\text { AGU: } \\
0\end{array}$ & GGU: 1 & CGU: 0 & UGU: 1 & & \\
\hline Val & AAC: 0 & GAC: 1 & CAC: 0 & UAC: 0 & & & Val & AAC: 0 & GAC: 0 & CAC: 0 & UAC: 0 & & \\
\hline Ser & AGA: 0 & GGA: 1 & CGA: 0 & UGA: 1 & ACU: 0 & GCU: 1 & Ser & AGA: 0 & GGA: 0 & CGA: 0 & UGA: 1 & ACU: 0 & GCU: 1 \\
\hline Arg & ACG: 1 & GCG: 0 & CCG:1 & UCG: 0 & CCU: 0 & UCU: 1 & Arg & ACG: 1 & GCG: 0 & CCG: 0 & UCG: 0 & CCU: 0 & UCU: 1 \\
\hline Leu & AAG: 0 & GAG: 0 & CAG: 0 & UAG: 1 & CAA: 2 & UAA: 0 & Leu & AAG: 0 & GAG: 0 & CAG: 0 & UAG: 1 & CAA: 1 & UAA: 1 \\
\hline Phe & AAA: 0 & GAA: 1 & & & & & Phe & $\begin{array}{c}\text { AAA: } \\
0\end{array}$ & GAA: 1 & & & & \\
\hline Asn & AUU: 0 & GUU: 1 & & & & & Asn & $\begin{array}{c}\text { AUU: } \\
0\end{array}$ & GUU: 1 & & & & \\
\hline Lys & CUU: 0 & UUU: 1 & & & & & Lys & $\begin{array}{c}\text { CUU: } \\
0\end{array}$ & UUU: 1 & & & & \\
\hline Asp & AUC: 0 & GUC: 1 & & & & & Asp & AUC: 0 & GUC: 1 & & & & \\
\hline Glu & CUC: 0 & UUC: 1 & & & & & Glu & CUC: 0 & UUC: 1 & & & & \\
\hline His & AUG: 0 & GUG: 2 & & & & & His & $\begin{array}{c}\text { AUG: } \\
0\end{array}$ & GUG: 1 & & & & \\
\hline Gln & CUG: 0 & UUG: 1 & & & & & Gln & CUG: 0 & UUG: 1 & & & & \\
\hline Ile & AAU: 0 & $\begin{array}{c}\text { GAU: } \\
\underline{0} 1\end{array}$ & CAU: 1 & UAU: 0 & & & Ile & $\begin{array}{c}\text { AAU: } \\
1\end{array}$ & GAU: 0 & CAU: 2 & UAU: 1 & & \\
\hline Met & CAU: 2 & & & & & & Met & CAU: 2 & & & & & \\
\hline Tyr & AUA: 1 & GUA: 1 & & & & & Tyr & $\begin{array}{c}\text { AUA: } \\
0\end{array}$ & GUA: 1 & & & & \\
\hline Cys & ACA: 1 & GCA: 1 & & & & & Cys & ACA: 0 & GCA: 1 & & & & \\
\hline $\operatorname{Trp}$ & CCA: 1 & & & & & & Trp & CCA: 1 & & & & & \\
\hline Supressor & CUA: 0 & UUA: 0 & UCA: 0 & & & & $\begin{array}{c}\text { Supresso } \\
\mathrm{r}\end{array}$ & CUA: 0 & UUA: 0 & UCA: 0 & & & \\
\hline $\mathrm{Sec}$ & UCA: 0 & & & & & & $\mathrm{Sec}$ & UCA: 0 & & & & & \\
\hline \multicolumn{7}{|c|}{ C. deodara (29) } & \multicolumn{7}{|c|}{ W. mirabilis (29) } \\
\hline Ala & AGC: 0 & GGC: 0 & CGC: 0 & UGC: 1 & & & Ala & AGC: 0 & GGC: 0 & CGC: 0 & UGC: 1 & & \\
\hline Gly & ACC: 0 & GCC: 1 & CCC: 0 & UCC: 1 & & & Gly & ACC: 0 & GCC: 1 & CCC: 0 & UCC: 1 & & \\
\hline Pro & AGG: 0 & GGG: 1 & CGG: 0 & UGG: 1 & & & Pro & AGG: 0 & GGG: 1 & CGG: 0 & UGG: 1 & & \\
\hline Thr & AGU: 0 & GGU: 1 & CGU: 0 & UGU: 1 & & & Thr & $\begin{array}{c}\text { AGU: } \\
0\end{array}$ & GGU: 1 & CGU: 0 & UGU: 1 & & \\
\hline Val & AAC: 0 & GAC: 1 & CAC: 0 & UAC: 0 & & & Val & AAC: 0 & GAC: 1 & CAC: 0 & UAC: 1 & & \\
\hline Ser & AGA: 0 & GGA: 1 & CGA: 0 & UGA: 1 & ACU: 0 & GCU: 1 & Ser & AGA: 0 & GGA: 1 & CGA: 0 & UGA: 1 & ACU: 0 & GCU: 1 \\
\hline Arg & ACG: 1 & GCG: 0 & CCG:1 & UCG: 0 & CCU: 0 & UCU: 1 & Arg & ACG: 1 & GCG: 0 & CCG: 2 & UCG: 0 & CCU: 0 & UCU: 1 \\
\hline
\end{tabular}




\begin{tabular}{|c|c|c|c|c|c|c|c|c|c|c|c|c|c|}
\hline Leu & AAG: 0 & GAG: 0 & CAG: 0 & UAG: 1 & CAA: 1 & UAA: 1 & Leu & AAG: 0 & GAG: 0 & CAG: 0 & UAG: 1 & CAA: 1 & UAA: 1 \\
\hline Phe & AAA: 0 & GAA: 1 & & & & & Phe & $\begin{array}{c}\text { AAA: } \\
0\end{array}$ & GAA: 1 & & & & \\
\hline Asn & AUU: 0 & GUU: 1 & & & & & Asn & $\begin{array}{c}\text { AUU: } \\
0\end{array}$ & GUU: 1 & & & & \\
\hline Lys & CUU: 0 & UUU: 1 & & & & & Lys & $\begin{array}{c}\text { CUU: } \\
0\end{array}$ & UUU: 1 & & & & \\
\hline Asp & AUC: 0 & GUC: 1 & & & & & Asp & AUC: 0 & GUC: 1 & & & & \\
\hline Glu & CUC: 0 & UUC: 2 & & & & & Glu & CUC: 0 & UUC: 2 & & & & \\
\hline His & AUG: 0 & GUG: 1 & & & & & His & $\begin{array}{c}\text { AUG: } \\
0\end{array}$ & GUG: 1 & & & & \\
\hline Gln & CUG: 0 & UUG: 1 & & & & & Gln & CUG: 0 & UUG: 1 & & & & \\
\hline Ile & AAU: 0 & GAU: 0 & CAU: 1 & UAU: 0 & & & Ile & $\begin{array}{c}\text { AAU: } \\
0\end{array}$ & GAU: 0 & CAU: 1 & UAU: 0 & & \\
\hline Met & CAU: 2 & & & & & & Met & CAU: 2 & & & & & \\
\hline Tyr & AUA: 0 & GUA: 1 & & & & & Tyr & $\begin{array}{c}\text { AUA: } \\
0\end{array}$ & GUA: 1 & & & & \\
\hline Cys & ACA: 0 & GCA: 1 & & & & & Cys & ACA: 0 & GCA: 1 & & & & \\
\hline $\operatorname{Trp}$ & CCA: 1 & & & & & & Trp & CCA: 1 & & & & & \\
\hline Supressor & CUA: 0 & UUA: 0 & UCA: 0 & & & & $\begin{array}{c}\text { Supresso } \\
\mathrm{r}\end{array}$ & CUA: 0 & UUA: 0 & UCA: 0 & & & \\
\hline $\mathrm{Sec}$ & UCA: 0 & & & & & & $\mathrm{Sec}$ & UCA: 0 & & & & & \\
\hline \multicolumn{7}{|c|}{ W. nobilis (30) } & \multicolumn{7}{|c|}{ G. gnemon (30) } \\
\hline Ala & AGC: 0 & GGC: 0 & CGC: 0 & UGC: 1 & & & Ala & AGC: 0 & GGC: 0 & CGC: 0 & UGC: 1 & & \\
\hline Gly & ACC: 0 & GCC: 1 & CCC: 0 & UCC: 1 & & & Gly & ACC: 0 & GCC: 1 & CCC: 0 & UCC: 1 & & \\
\hline Pro & AGG: 0 & GGG: 1 & CGG: 0 & UGG: 1 & & & Pro & AGG: 0 & GGG: 1 & CGG: 0 & UGG: 1 & & \\
\hline Thr & AGU: 0 & GGU: 1 & CGU: 0 & UGU: 1 & & & Thr & $\begin{array}{c}\text { AGU: } \\
0\end{array}$ & GGU: 1 & CGU: 0 & UGU: 1 & & \\
\hline Val & AAC: 0 & GAC: 1 & CAC: 0 & UAC: 0 & & & Val & AAC: 0 & GAC: 1 & CAC: 0 & UAC: 1 & & \\
\hline Ser & AGA: 0 & GGA: 1 & CGA: 1 & UGA: 1 & ACU: 0 & GCU: 1 & Ser & AGA: 0 & GGA: 1 & CGA: 0 & UGA: 1 & ACU: 0 & GCU: 1 \\
\hline Arg & ACG: 1 & GCG: 0 & CCG:1 & UCG: 0 & CCU: 0 & UCU: 1 & Arg & ACG: 1 & GCG: 0 & CCG:1 & UCG: 0 & CCU: 0 & UCU: 1 \\
\hline Leu & AAG: 0 & GAG: 0 & CAG: 0 & UAG: 1 & CAA: 1 & UAA: 1 & Leu & AAG: 0 & GAG: 0 & CAG: 0 & UAG: 1 & CAA: 1 & UAA: 1 \\
\hline Phe & AAA: 0 & GAA: 1 & & & & & Phe & $\begin{array}{c}\text { AAA: } \\
0\end{array}$ & GAA: 1 & & & & \\
\hline Asn & AUU: 0 & GUU: 1 & & & & & Asn & $\begin{array}{c}\text { AUU: } \\
0\end{array}$ & GUU: 1 & & & & \\
\hline
\end{tabular}




\begin{tabular}{|c|c|c|c|c|c|c|c|c|c|c|c|c|c|}
\hline Lys & CUU: 0 & UUU: 1 & & & & & Lys & $\begin{array}{c}\text { CUU: } \\
0\end{array}$ & UUU: 1 & & & & \\
\hline Asp & AUC: 0 & GUC: 1 & & & & & Asp & AUC: 0 & GUC: 1 & & & & \\
\hline Glu & CUC: 0 & UUC: 2 & & & & & Glu & CUC: 0 & UUC: 2 & & & & \\
\hline His & AUG: 0 & GUG: 1 & & & & & His & $\begin{array}{c}\text { AUG: } \\
0\end{array}$ & GUG: 1 & & & & \\
\hline Gln & CUG: 0 & UUG: 1 & & & & & Gln & CUG: 0 & UUG: 1 & & & & \\
\hline Ile & AAU: 0 & GAU: 0 & CAU: 1 & UAU: 0 & & & Ile & $\begin{array}{c}\text { AAU: } \\
0\end{array}$ & GAU: 0 & CAU: 1 & UAU: 0 & & \\
\hline Met & CAU: 2 & & & & & & Met & CAU: 2 & & & & & \\
\hline Tyr & AUA: 0 & GUA: 1 & & & & & Tyr & $\begin{array}{c}\text { AUA: } \\
0\end{array}$ & GUA: 1 & & & & \\
\hline Cys & ACA: 0 & GCA: 1 & & & & & Cys & ACA: 0 & GCA: 1 & & & & \\
\hline $\operatorname{Trp}$ & CCA: 1 & & & & & & Trp & CCA: 1 & & & & & \\
\hline Supressor & CUA: 0 & UUA: 0 & UCA: 0 & & & & $\begin{array}{c}\text { Supresso } \\
\mathrm{r}\end{array}$ & CUA: 0 & UUA: 0 & UCA: 0 & & & \\
\hline $\mathrm{Sec}$ & UCA: 0 & & & & & & $\mathrm{Sec}$ & UCA: 0 & & & & & \\
\hline \multicolumn{7}{|c|}{ R.piresii (29) } & \multicolumn{5}{|c|}{ E. equisetina (25) } & & \\
\hline Ala & AGC: 0 & GGC: 0 & CGC: 0 & UGC: 0 & & & Ala & AGC: 0 & GGC: 0 & CGC: 0 & UGC: 1 & & \\
\hline Gly & ACC: 0 & GCC: 1 & CCC: 0 & UCC: 1 & & & Gly & ACC: 0 & GCC: 1 & CCC: 0 & UCC: 0 & & \\
\hline Pro & AGG: 0 & GGG: 1 & CGG: 0 & UGG: 1 & & & Pro & AGG: 0 & GGG: 0 & CGG: 0 & UGG: 1 & & \\
\hline Thr & AGU: 0 & GGU: 1 & CGU: 0 & UGU: 1 & & & Thr & $\begin{array}{c}\text { AGU: } \\
0\end{array}$ & GGU: 1 & CGU: 0 & UGU: 0 & & \\
\hline Val & AAC: 0 & GAC: 1 & CAC: 0 & UAC: 1 & & & Val & AAC: 0 & GAC: 1 & CAC: 0 & UAC: 0 & & \\
\hline Ser & AGA: 0 & GGA: 1 & CGA: 0 & UGA: 1 & ACU: 0 & GCU: 1 & Ser & AGA: 0 & GGA: 1 & CGA: 0 & UGA: 1 & ACU: 0 & GCU: 1 \\
\hline Arg & ACG: 1 & GCG: 0 & CCG:1 & UCG: 0 & CCU: 0 & UCU: 1 & Arg & ACG: 1 & GCG: 0 & CCG:0 & UCG: 0 & CCU: 0 & UCU: 1 \\
\hline Leu & AAG: 0 & GAG: 0 & CAG: 0 & UAG: 1 & CAA: 1 & UAA: 1 & Leu & AAG: 0 & GAG: 0 & CAG: 0 & UAG: 1 & CAA: 1 & UAA: 1 \\
\hline Phe & AAA: 0 & GAA: 1 & & & & & Phe & $\begin{array}{c}\text { AAA: } \\
0\end{array}$ & GAA: 1 & & & & \\
\hline Asn & AUU: 0 & GUU: 1 & & & & & Asn & $\begin{array}{c}\text { AUU: } \\
0\end{array}$ & GUU: 1 & & & & \\
\hline Lys & CUU: 0 & UUU: 1 & & & & & Lys & $\begin{array}{c}\text { CUU: } \\
0\end{array}$ & UUU: 1 & & & & \\
\hline Asp & AUC: 0 & GUC: 2 & & & & & Asp & AUC: 0 & GUC: 1 & & & & \\
\hline Glu & CUC: 0 & UUC: 2 & & & & & Glu & CUC: 0 & UUC: 2 & & & & \\
\hline His & AUG: 0 & GUG: 1 & & & & & His & AUG: & GUG: 1 & & & & \\
\hline
\end{tabular}




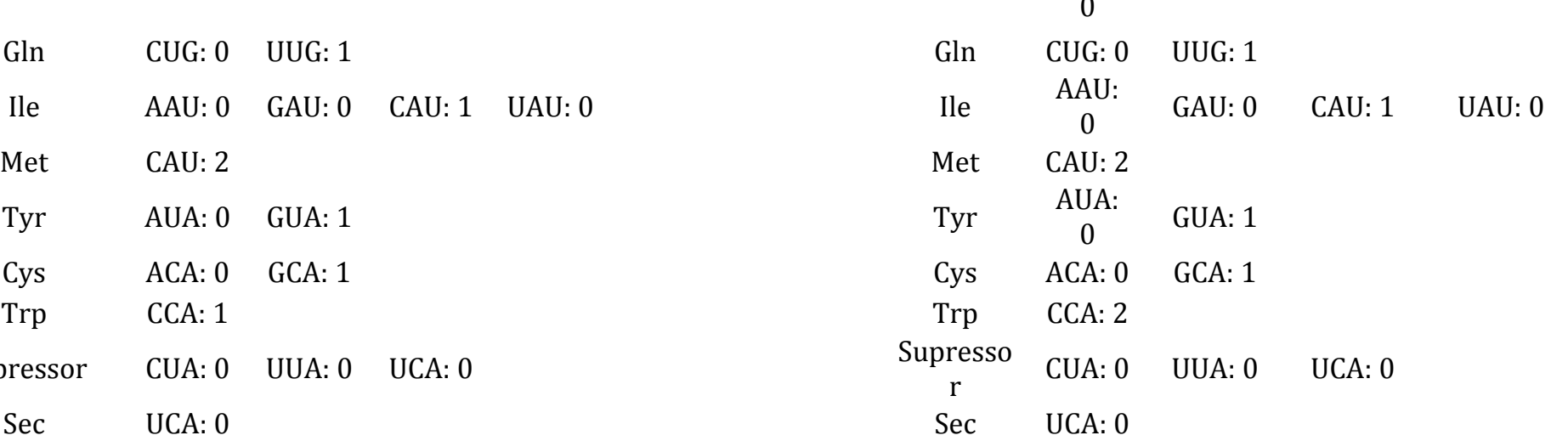




\section{Table 4 (on next page)}

Conserved sequence motifs in chloroplast tRNAs from gymnosperms.

Small conserved consensus motifs were observed in the $\Psi$ region. To be specific, except for tRNA $^{\text {Ser }}$, the $\Psi$-loop in tRNAs was found to contain a conserved sequence comprising U-U-C-NA- $\mathrm{N}_{2}$ according to a multiple sequence alignment of 20 members of the tRNA gene family. 
1 Table 4. Conserved sequence motifs in chloroplast tRNAs from gymnosperms.

\begin{tabular}{|c|c|c|c|c|c|c|c|c|}
\hline tRNA Isotypes & $5^{\prime} \mathrm{AC}$-arm & D-arm & D-loop & ANC-arm & ANC-loop & Variable region & $\Psi$-arm & $\Psi$-loop \\
\hline \multirow[b]{2}{*}{ Alanine } & 5'-G-G-G-G-A-U-A & 5'-G-C-U-C & & 5'-C-C-G-C-U & & & $5^{\prime}-A-G-C-G-G$ & \\
\hline & 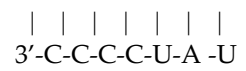 & $\begin{array}{c}|||||| \\
3^{\prime}-C-G-A-G\end{array}$ & 5'-A-G-U-U-G-G-U-A & $\begin{array}{c}|+||||| \\
\text { 3'-G-G-C-G-A }\end{array}$ & 5'-C-U-U-G-C-A-U & 5'-A-U-G-U-C & $\begin{array}{c}|+||||||+| \\
\text { 3'-U-C-G-C-C }\end{array}$ & 5'-U-U-C-G-A-G-U \\
\hline \multirow{4}{*}{ Arginine } & $\mathrm{N}_{2}-\mathrm{G}-\mathrm{N}_{3}-\mathrm{G}$ & $\mathrm{G}-\mathrm{N}_{3}$ & & $\mathrm{~N}_{3}-\mathrm{G}-\mathrm{N}$ & & & $\mathrm{N}_{3}-\mathrm{G}-\mathrm{N}$ & \\
\hline & $1 \quad 1 \quad 1$ & $\mid$ & A- $\mathrm{N}_{2}-\mathrm{G}-\mathrm{G}-\mathrm{A}-\mathrm{N}_{1-2}-\mathrm{A}$ & | | | & N-U-N-C-N-A-A & $* * * * *$ & | | | & U-U-C-N-A-A-U \\
\hline & $\mathrm{N}_{2}-\mathrm{C}-\mathrm{N}_{3}-\mathrm{C}$ & $\mathrm{C}-\mathrm{N}_{3}$ & & $\mathrm{~N}_{3}-\mathrm{C}-\mathrm{N}$ & & & $\mathrm{N}_{3}-\mathrm{C}-\mathrm{N}$ & \\
\hline & U-C-C-N-C-A-N & G-C-U-C & & G-U-C-G-G & & & G-U-A-G-G & \\
\hline \multirow[t]{2}{*}{ Asparagine } & $\begin{array}{cccccc}\mid & \mid & \mid & \mid & \mid & \mid \\
\text { A-G-G-N-G-U-U-N }\end{array}$ & $\begin{array}{l}|+||| \\
C-G-A-G\end{array}$ & A-G-N-G-G-U-A & 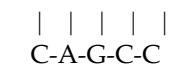 & C-U-G-U-U-A-A & U-N ${ }_{1-3-} \mathrm{G}-\mathrm{U}-\mathrm{C}$ & $\begin{array}{cccc}\mid & \mid & \mid & \mid \\
C-A-U-C-C\end{array}$ & U-U-C-A-A-A-U \\
\hline & G-G-G-A-U-U-G & G-U-U-C & & C-C-G-N-C & & & G-C-G-G-G & \\
\hline \multirow[t]{2}{*}{ Aspartate } & $\begin{array}{cccccc}\mid & \mid & \mid & \mid & \mid & \mid \\
C-C-C-U-A-A & \mid\end{array} \mid$ & 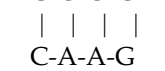 & A-A-U-U-N-G-U-U-A & \begin{tabular}{ccc|c|}
$\mid$ & $\mid$ & $\mid$ & $\mid$ \\
G-G-C-N-G
\end{tabular} & C-U-G-U-C-A-A & A-A-G-U-U & $\begin{array}{ccc}\mid & \mid & \mid \\
C-G-C-C-C & \mid\end{array}$ & U-U-C-G-A-G-N \\
\hline & G-G-C-G-N-C-A & G-C-C & & $\mathrm{G}-\mathrm{N}_{2-3}-\mathrm{A}$ & & & C-C-C-N-G & \\
\hline Cysteine & \begin{tabular}{ccccc|c}
$\mid$ & $\mid$ & $\mid$ & $\mid$ & $\mid$ & $\mid$ \\
$C-C-G-C-N-G-U$
\end{tabular} & $\begin{array}{l}\mid \\
\text { C-G-G }\end{array}$ & A-A-G-N-G-G-U-A-A & $\begin{array}{c}|+| \\
C-N_{2-3}-U\end{array}$ & C-U-A-C-A-A-A & $* * * *$ & $\mid$\begin{tabular}{cc|}
$\mid$ & $\mid$ \\
G-G-G-N-C
\end{tabular} & U-U-C-G-A-A-U \\
\hline Glutamate & $\begin{array}{l}\text { U-G-G-G-G-C-G } \\
\mid \begin{array}{lllll}\mid & \mid & \mid & \mid & \mid \\
\text { A-C-C-C-C-G-C }\end{array}\end{array}$ & $\begin{array}{l}\text { G-C-C } \\
|\quad||| \\
C-G-G\end{array}$ & A-A-G-N-G-G-U-A-A & $\begin{array}{l}\text { N-C-A-G-G } \\
\mid \begin{array}{llll}\mid & \mid & \mid \\
\text { N-G-U-C-C }\end{array}\end{array}$ & U-U-U-U-G-N-U & U-A-N-U-N ${ }_{1-2}$ & 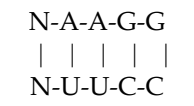 & U-U-C-G-A-A-U \\
\hline \multirow[t]{2}{*}{ Glutamine } & $\begin{array}{c}\mathrm{G}-\mathrm{N}_{2}-\mathrm{C}-\mathrm{N}_{3} \\
|+||| \\
\mathrm{C}-\mathrm{N}_{2}-\mathrm{G}-\mathrm{N}_{3}\end{array}$ & $\begin{array}{l}\mathrm{G}-\mathrm{N}_{3} \\
|| \\
\mathrm{C}-\mathrm{N}_{3}\end{array}$ & A-G-N-G-G-N ${ }_{2-4}$ & $* * * * *$ & C-U-U-U-C-A-N & $* * * *$ & $\begin{array}{c}\mathrm{N}_{3}-\mathrm{G}-\mathrm{G} \\
|\quad| \quad \mid \\
\mathrm{N}_{3}-\mathrm{C}-\mathrm{C}\end{array}$ & U-U-C-N-A-N-U \\
\hline & G-C-G-G-N-U-A & G-U-U & & U-C-U-C-N & & & G-C-G-G-G & \\
\hline Glycine & \begin{tabular}{ccccc|c}
$\mid$ & $\mid$ & $\mid$ & $\mid$ & $\mid$ & $\mid$ \\
$C-G-C-C-N-A-U$
\end{tabular} & $\begin{array}{l}|\quad| \\
\text { C-A-A }\end{array}$ & $\mathrm{N}-\mathrm{A}-\mathrm{N}_{5-14}$ & 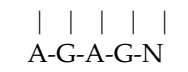 & U-U-G-C-C-A-N & A-G-A-N & 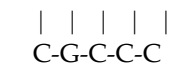 & U-U-C-G-A-U-N \\
\hline Histidine & 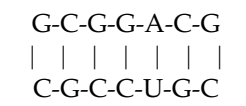 & $\begin{array}{l}\text { G-C-C } \\
|\quad| \quad \mid \\
C-G-G\end{array}$ & A-A-G-U-G-G-N $\mathrm{N}_{2-4}-\mathrm{A}-\mathrm{A}$ & $\begin{array}{l}\text { G-U-G-G-A } \\
\mid \begin{array}{llll}\mid & \mid & \mid & \mid \\
\text { C-A-C-C-U }\end{array}\end{array}$ & U-U-G-U-G-G-A & C-A-C-G-C & $\begin{array}{l}\text { G-C-G-G-G } \\
\mid \begin{array}{lll|l}\mid & \mid & \mid & \mid \\
C-G-C-C-C\end{array}\end{array}$ & U-U-C-A-A-U-C \\
\hline Isoleucine & $\begin{array}{l}\text { G-C-A-U-C-C-A } \\
\left|\begin{array}{llllll}\mid & \mid & \mid & \mid & \mid & \mid\end{array}\right| \\
\text { C-G-U-A-G-G-U-U }\end{array}$ & $\begin{array}{l}\text { G-C-U-C } \\
|\quad| \quad|\quad| \\
\text { C-G-A-G }\end{array}$ & G-A-A-U-G-G-U-A-A-A & $\begin{array}{l}\text { C-C-C-A-A } \\
\begin{array}{llll|l}\mid & \mid & \mid & \mid & \mid \\
\text { G-G-G-U-U }\end{array}\end{array}$ & C-U-C-A-A-U-A-A & A-A-N-U-C & $\begin{array}{l}\text { G-C-N-G-G } \\
\mid \begin{array}{llll}\mid & \mid & \mid & \mid \\
C-G-N-C-C\end{array}\end{array}$ & U-U-C-A-A-U-U \\
\hline \multirow[t]{2}{*}{ Leucine } & $\begin{array}{c}\mathrm{G}-\mathrm{N}_{5}-\mathrm{A} \\
|\quad| \quad \mid \\
\mathrm{C}-\mathrm{N}_{5}-\mathrm{U}\end{array}$ & $\begin{array}{l}\text { G-N-G } \\
|\quad| \quad \mid \\
\text { C-N-C }\end{array}$ & N-A-A-U-N-G-U-A-G-A & $* * * * * *$ & C-U-N-A-N $2-A$ & $\begin{array}{c}\text { U-G-N-U-N }{ }_{3-9-\mathrm{G}-\mathrm{C}-\mathrm{N}-} \\
\mathrm{U}\end{array}$ & $\begin{array}{c}\mathrm{N}_{3}-\mathrm{G}-\mathrm{G} \\
|||| \mid \\
\mathrm{N}_{3}-\mathrm{C}-\mathrm{C}\end{array}$ & U-U-C-N-A-N-U \\
\hline & G-G-G-U-U-G-C & A-C-U-C & & U-C-G-G & & & C-C-G-G-G & \\
\hline Lysine & 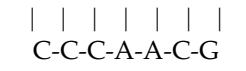 & $\begin{array}{l}|\quad| \quad|\quad| \\
\text { U-G-A-G }\end{array}$ & A-A-U-G-G-U-A & $\begin{array}{l}|\quad| \quad|| \mid \\
\text { A-G-C-C }\end{array}$ & C-U-U-U-U-A-A & $\mathrm{N}_{2}-\mathrm{A}-\mathrm{G}-\mathrm{N}-\mathrm{U}$ & $\begin{array}{l}\mid \\
\text { G-G-C-C-C }\end{array}$ & U-U-C-N-A-N-U \\
\hline Methionine & $\begin{array}{c}\mathrm{N}-\mathrm{C}-\mathrm{N}_{3-4} \\
|||| \\
\mathrm{N}-\mathrm{G}-\mathrm{N}_{3-4}\end{array}$ & $* * * *$ & $\mathrm{~N}_{4-5}-\mathrm{G}-\mathrm{G}-\mathrm{U}-\mathrm{N}_{1-3}$ & $* * * * *$ & N-U-C-A-U-A-N & $\mathrm{N}_{3}-\mathrm{U}-\mathrm{C}$ & $\begin{array}{c}\mathrm{N}_{3}-\mathrm{G}-\mathrm{G} \\
|||| \\
\mathrm{N}_{3}-\mathrm{C}-\mathrm{C}\end{array}$ & U-U-C-A-A-N-U \\
\hline Phenylalanine & 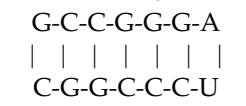 & $\begin{array}{l}\text { G-C-U-C } \\
|\quad| \quad|\quad| \\
\text { C-G-A-G }\end{array}$ & A-G-U-U-G-G-U-A & $\begin{array}{l}\text { G-A-G-G-A } \\
\mid \begin{array}{lll|}\mid & \mid & \mid \\
\text { C-U-C-C-U }\end{array}\end{array}$ & C-U-G-A-A-A-A & G-U-G-C-C & $\begin{array}{l}\text { A-C-C-A-G } \\
\mid \begin{array}{llll}\mid & \mid & \mid & \mid \\
\text { U-G-G-U-C }\end{array}\end{array}$ & U-U-C-A-A-A-U \\
\hline Proline & $\begin{array}{l}\text { N-G-G-N } \\
|\quad| \quad|\quad|\end{array}$ & $\begin{array}{l}\text { N-C-G-C } \\
\mid \begin{array}{lll}\mid & \mid & \mid\end{array}\end{array}$ & A-G-N-U-U-G-G-U-A & $* * * * *$ & N-U-N-G-G-G-U & A-N-G-U-C & $\begin{array}{c}\mathrm{N}_{3}-\mathrm{G}-\mathrm{G} \\
|| \mid\end{array}$ & U-U-C-A-A-N-U \\
\hline
\end{tabular}




\begin{tabular}{|c|c|c|c|c|c|c|c|c|}
\hline & N-C-C-N 4 & N-G-C-G & & & & & $\mathrm{N}_{3}-\mathrm{C}-\mathrm{C}$ & \\
\hline Serine & $\begin{array}{l}\mathrm{G}-\mathrm{N}_{5}-\mathrm{A} \\
\mid \begin{array}{l}\mid \\
\mathrm{C}-\mathrm{N}_{5}-\mathrm{U}\end{array}\end{array}$ & $\begin{array}{c}\mathrm{G}-\mathrm{N}_{2-3} \\
|| \mid \\
\mathrm{C}-\mathrm{N}_{2-3}\end{array}$ & $* * * * * * * * * * * * *$ & $\begin{array}{c}\mathrm{N}_{2}-\mathrm{G}-\mathrm{N}_{1-2} \\
|\quad| \quad \mid \\
\mathrm{N}_{2}-\mathrm{C}-\mathrm{N}_{1-2}\end{array}$ & $\mathrm{~N}-\mathrm{U}-\mathrm{N}_{3}-\mathrm{A}-\mathrm{N}$ & $* * * * * * * * * * * * * * * * * * * * *$ & 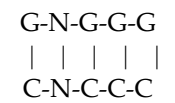 & U-U-C-G-N ${ }_{2}-\mathrm{U}$ \\
\hline & G-C-N ${ }_{2}-\mathrm{G}-\mathrm{N}_{2}$ & N-C-U-C & & N-C-G-C-N & & & N-U-N-G-G & \\
\hline Threonine & 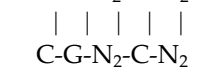 & $\begin{array}{llll}\mid & 1 & 1 & 1 \\
\text { N-G-A-G }\end{array}$ & A-G-N-G-G-U-N $0_{0-1}-A$ & $\begin{array}{cccc}\mid & 1 & 1 & \mid \\
\text { N-G-C-G-N }\end{array}$ & $\mathrm{N}-\mathrm{U}-\mathrm{N}_{3}-\mathrm{A}-\mathrm{A}$ & $\mathrm{N}_{2}$-G-U-C & $\begin{array}{cccc}\mid & 1 & 1 & \mid \\
\text { N-A-N-C-C }\end{array}$ & U-U-C-N-A-N \\
\hline Tryptophan & $\begin{array}{l}\text { G-C-G-C-U-C-U } \\
\left|\begin{array}{lllll}\mid & \mid & \mid & \mid & \mid\end{array}\right|\end{array}$ & $\begin{array}{l}\text { G-U-U-N } \\
|||||| l \mid l\end{array}$ & A-G-N ${ }_{3}-\mathrm{G}-\mathrm{G}-\mathrm{U}-\mathrm{A}$ & $\mathrm{N}_{2}$-G-G-U & C-U-C-C-A-A-A & A-U-G-N-C & G-U-A-G-G & U-U-C-A-A-A-U \\
\hline & C-G-C-G-A-G-A & C-A-A-N & & $\mathrm{N}_{2}-\mathrm{C}-\mathrm{C}-\mathrm{A}$ & & & C-A-U-C-C & \\
\hline Tyrosine & 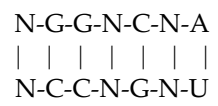 & 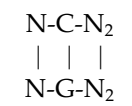 & A-G-N $\mathrm{N}_{6}-\mathrm{A}$ & $* * * * *$ & C-U-G-U-A-A-A & $* * * *$ & $\begin{array}{c}\mathrm{N}_{3}-\mathrm{G}-\mathrm{G} \\
|\quad| \quad \mid \\
\mathrm{N}_{3}-\mathrm{C}-\mathrm{C}\end{array}$ & U-U-C-N-A-N \\
\hline Valine & 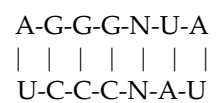 & 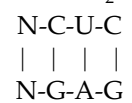 & A-G-N $\mathrm{N}_{4 \cdot 6}$ A & 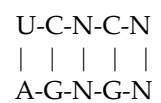 & U-U-N-A-C-N 2 & $\mathrm{~N}_{2-3}-\mathrm{G}-\mathrm{U}-\mathrm{C}$ & 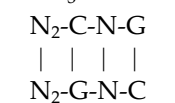 & U-U-C-N-A-N \\
\hline
\end{tabular}

2 Note that the consensus sequences are shown from 5' to 3'. The asterisk mark $\left.{ }^{*}\right)$ show the absence of conserved nucleotide consensus 3 sequence in respective region of chloroplast tRNAs. 5' AC-arm, 5' Acceptor arm; ANC-arm, Anti-codon arm; ANC-loop, Anti-codon 4 loop; $\Psi$-arm, Pseudouridine arm; $\Psi$-loop, Pseudouridine loop. The short lines under the bases in anticodon loop of tRNA ${ }^{\text {Ile }}$ are to 5 indicate its possible modification. 


\section{Table 5 (on next page)}

Transition and transversion rate of chloroplast tRNA.

In all of the chloroplast tRNAs, the average transition rate was slightly higher than the average transversion rate, thereby indicating that chloroplast tRNAs have unequal substitution rates. 
1 Table 5. Transition and transversion rate of chloroplast tRNA.

\begin{tabular}{|c|c|c|c|c|c|c|c|c|c|}
\hline \multicolumn{6}{|c|}{ Alanine } & \multicolumn{4}{|c|}{ lysine } \\
\hline From/To & A & $\mathrm{U}$ & $\mathrm{C}$ & G & From/To & A & $\mathrm{U}$ & $\mathrm{C}$ & G \\
\hline $\mathrm{A}$ & - & 12.50 & 12.50 & 0.00 & $\mathrm{~A}$ & - & 1.47 & 1.47 & 22.06 \\
\hline $\mathrm{U}$ & 12.50 & - & 0.00 & 12.50 & $\mathrm{U}$ & 1.47 & - & 22.06 & 1.47 \\
\hline C & 12.50 & 0.00 & - & 12.50 & $\mathrm{C}$ & 1.47 & 22.06 & - & 1.47 \\
\hline G & 0.00 & 12.50 & 12.50 & - & G & 22.06 & 1.47 & 1.47 & - \\
\hline \multicolumn{6}{|c|}{ Arginine } & \multicolumn{4}{|c|}{ Methionine } \\
\hline From/To & A & $\mathrm{U}$ & $\mathrm{C}$ & G & From/To & A & $\mathrm{U}$ & $\mathrm{C}$ & G \\
\hline A & - & 2.93 & 2.93 & 19.13 & A & - & 3.86 & 3.86 & 17.27 \\
\hline $\mathrm{U}$ & 2.93 & - & 19.13 & 2.93 & $\mathrm{U}$ & 3.86 & - & 17.27 & 3.86 \\
\hline $\mathrm{C}$ & 2.93 & 19.13 & - & 2.93 & $\mathrm{C}$ & 3.86 & 17.27 & - & 3.86 \\
\hline G & 19.13 & 2.93 & 2.93 & - & G & 17.27 & 3.86 & 3.86 & - \\
\hline \multicolumn{6}{|c|}{ Asparagine } & \multicolumn{4}{|c|}{ Phenylalanine } \\
\hline From/To & A & $\mathrm{U}$ & C & $\mathrm{G}$ & From/To & A & $\mathrm{U}$ & C & G \\
\hline $\mathrm{A}$ & - & 1.12 & 1.12 & 22.75 & $\mathrm{~A}$ & - & 1.21 & 1.21 & 22.58 \\
\hline $\mathrm{U}$ & 1.12 & - & 22.75 & 1.12 & $\mathrm{U}$ & 1.21 & - & 22.58 & 1.21 \\
\hline $\mathrm{C}$ & 1.12 & 22.75 & - & 1.12 & C & 1.21 & 22.58 & - & 1.21 \\
\hline G & 22.75 & 1.12 & 1.12 & - & G & 22.58 & 1.21 & 1.21 & - \\
\hline \multicolumn{6}{|c|}{ Aspartate } & \multicolumn{4}{|c|}{ Proline } \\
\hline From/To & A & $\mathrm{U}$ & C & G & From/To & $\mathrm{A}$ & $\mathrm{U}$ & C & G \\
\hline $\mathrm{A}$ & - & 0.00 & 0.00 & 25.00 & A & - & 1.53 & 1.53 & 21.95 \\
\hline $\mathrm{U}$ & 0.00 & - & 25.00 & 0.00 & $\mathrm{U}$ & 1.53 & - & 21.95 & 1.53 \\
\hline $\mathrm{C}$ & 0.00 & 25.00 & - & 0.00 & C & 1.53 & 21.95 & - & 1.53 \\
\hline G & 25.00 & 0.00 & 0.00 & - & G & 21.95 & 1.53 & 1.53 & - \\
\hline \multicolumn{6}{|c|}{ Cysteine } & \multicolumn{4}{|c|}{ Serine } \\
\hline From/To & $\mathrm{A}$ & $\mathrm{U}$ & $C$ & $G$ & From/To & $\mathrm{A}$ & $\mathrm{U}$ & $C$ & $G$ \\
\hline A & - & 2.75 & 2.75 & 19.50 & A & - & 5.16 & 5.16 & 14.68 \\
\hline $\mathrm{U}$ & 2.75 & - & 19.50 & 2.75 & $\mathrm{U}$ & 5.16 & - & 14.68 & 5.16 \\
\hline $\mathrm{C}$ & 2.75 & 19.50 & - & 2.75 & $\mathrm{C}$ & 5.16 & 14.68 & - & 5.16 \\
\hline G & 19.50 & 2.75 & 2.75 & - & G & 14.68 & 5.16 & 5.16 & - \\
\hline \multicolumn{6}{|c|}{ Glutamine } & \multicolumn{4}{|c|}{ Threonine } \\
\hline From/To & $\mathrm{A}$ & $\mathrm{U}$ & $\mathrm{C}$ & $G$ & From/To & $\mathrm{A}$ & $\mathrm{U}$ & $C$ & G \\
\hline A & - & 3.83 & 3.83 & 17.35 & A & - & 3.91 & 3.91 & 17.18 \\
\hline $\mathrm{U}$ & 3.83 & - & 17.35 & 3.83 & $\mathrm{U}$ & 3.91 & - & 17.18 & 3.91 \\
\hline C & 3.83 & 17.35 & - & 3.83 & C & 3.91 & 17.18 & - & 3.91 \\
\hline G & 17.35 & 3.83 & 3.83 & - & G & 17.18 & 3.91 & 3.91 & - \\
\hline
\end{tabular}




\begin{tabular}{cccccccccc}
\hline \multicolumn{9}{c}{ Glutamate } & \multicolumn{4}{c}{ Ttyptophan } \\
\hline From/To & $\mathrm{A}$ & $\mathrm{U}$ & $\mathrm{C}$ & $\mathrm{G}$ & From/To & $\mathrm{A}$ & $\mathrm{U}$ & $\mathrm{C}$ & $\mathrm{G}$ \\
$\mathrm{A}$ & - & 4.59 & 4.59 & $\mathbf{1 5 . 8 1}$ & $\mathrm{A}$ & - & 2.02 & 2.02 & $\mathbf{2 0 . 9 6}$ \\
$\mathrm{U}$ & 4.59 & - & $\mathbf{1 5 . 8 1}$ & 4.59 & $\mathrm{U}$ & 2.02 & - & $\mathbf{2 0 . 9 6}$ & 2.02 \\
$\mathrm{C}$ & 4.59 & $\mathbf{1 5 . 8 1}$ & - & 4.59 & $\mathrm{C}$ & 2.02 & $\mathbf{2 0 . 9 6}$ & - & 2.02 \\
$\mathrm{G}$ & $\mathbf{1 5 . 8 1}$ & 4.59 & 4.59 & - & $\mathrm{G}$ & $\mathbf{2 0 . 9 6}$ & 2.02 & 2.02 & - \\
\hline
\end{tabular}

\begin{tabular}{cccccccccc}
\hline & \multicolumn{4}{c}{ Glycine } & \multicolumn{5}{c}{ Tyrosine } \\
\hline From/To & A & U & C & G & From/To & A & U & C & G \\
A & - & 1.94 & 1.94 & $\mathbf{2 1 . 1 3}$ & A & - & 5.34 & 5.34 & $\mathbf{1 4 . 3 3}$ \\
U & 1.94 & - & $\mathbf{2 1 . 1 3}$ & 1.94 & U & 5.34 & - & $\mathbf{1 4 . 3 3}$ & 5.34 \\
C & 1.94 & $\mathbf{2 1 . 1 3}$ & - & 1.94 & C & 5.34 & $\mathbf{1 4 . 3 3}$ & - & 5.34 \\
G & $\mathbf{2 1 . 1 3}$ & 1.94 & 1.94 & - & G & $\mathbf{1 4 . 3 3}$ & 5.34 & 5.34 & - \\
\hline & \multicolumn{4}{c}{ Histidine } & & & & Valine & \\
\hline From/To & A & U & C & G & From/To & A & U & C & G \\
A & - & 1.22 & 1.22 & $\mathbf{2 2 . 5 6}$ & A & - & 1.73 & 1.73 & $\mathbf{2 1 . 5 4}$ \\
U & 1.22 & - & $\mathbf{2 2 . 5 6}$ & 1.22 & U & 1.73 & - & $\mathbf{2 1 . 5 4}$ & 1.73 \\
C & 1.22 & $\mathbf{2 2 . 5 6}$ & - & 1.22 & C & 1.73 & $\mathbf{2 1 . 5 4}$ & - & 1.73 \\
G & $\mathbf{2 2 . 5 6}$ & 1.22 & 1.22 & - & G & $\mathbf{2 1 . 5 4}$ & 1.73 & 1.73 & - \\
\hline & & \multicolumn{2}{c}{ Isoleucine } & & & & Overrall & \\
\hline From/To & A & U & C & G & From/To & A & U & C & G \\
A & - & 4.72 & 4.72 & $\mathbf{1 5 . 5 6}$ & A & - & 4.81 & 4.81 & $\mathbf{1 5 . 3 8}$ \\
U & 4.72 & - & $\mathbf{1 5 . 5 6}$ & 4.72 & U & 4.81 & - & $\mathbf{1 5 . 3 8}$ & 4.81 \\
C & 4.72 & $\mathbf{1 5 . 5 6}$ & - & 4.72 & C & 4.81 & $\mathbf{1 5 . 3 8}$ & - & 4.81 \\
G & $\mathbf{1 5 . 5 6}$ & 4.72 & 4.72 & - & G & $\mathbf{1 5 . 3 8}$ & 4.81 & 4.81 & - \\
\hline
\end{tabular}

\begin{tabular}{ccccc}
\hline \multicolumn{5}{c}{ Leucine } \\
\hline From/To & $\mathrm{A}$ & $\mathrm{U}$ & $\mathrm{C}$ & $\mathrm{G}$ \\
$\mathrm{A}$ & - & 4.40 & 4.40 & $\mathbf{1 6 . 2 1}$ \\
$\mathrm{U}$ & 4.40 & - & $\mathbf{1 6 . 2 1}$ & 4.40 \\
$\mathrm{C}$ & 4.40 & $\mathbf{1 6 . 2 1}$ & - & 4.40 \\
$\mathrm{G}$ & $\mathbf{1 6 . 2 1}$ & 4.40 & 4.40 & \\
\hline
\end{tabular}

